\title{
" $\mathrm{N}$ "-shaped $\mathrm{Y} / \mathrm{X}$ coda spectral ratio observed for in-line-type OBS networks; S-net and ETMC: interpretation based on natural vibration of pressure vessel
}

\author{
Kaoru Sawazaki ${ }^{*}$ (10 and Takeshi Nakamura ${ }^{2}$
}

\begin{abstract}
We have identified " $\mathrm{N}$ "-shaped $\mathrm{Y} / \mathrm{X}$ amplitude spectral ratios in S-coda records from a significant number of OBSs (ocean bottom seismometers) belonging to in-line-type ocean bottom networks of S-net and ETMC deployed around the Japan Trench and Sagami Trough, respectively. The " $\mathrm{N}$ "-shape reflects a sharp peak and notch at approximately 5-13 Hz and 10-23 Hz, respectively. This shape does not characterize OBSs belonging to node-type ocean bottom network of DONET deployed near the Nankai Trough. For S-net stations, the " $\mathrm{N}$ "-shape is not clearly formed for stations installed within grooves dug in the seafloor. We interpret the " $\mathrm{N}$ "-shaped $\mathrm{Y} / \mathrm{X}$ amplitude spectral ratio is caused by the natural vibrations of a cylindrical pressure vessel that is placed sideways (long-axis lies in the horizontal plane) on the seafloor. The notch and peak frequencies in the $Y / X$ amplitude spectral ratio likely correspond to natural frequencies of longitudinal (X-direction) and torsional and/or bending (Y-direction) vibrations, respectively. These natural vibrations are not observed for buried OBSs or those installed within grooves in the seafloor probably because they are better coupled to the seafloor. We propose a simple model to evaluate the extent to which the peak and notch have formed, which depends on the natural frequencies and coupling of the pressure vessel. We suggest users of inline-type OBSs carefully examine if there are different responses between the $X$ and $Y$ components when frequencies about $>3 \mathrm{~Hz}$ are used. When installing OBS networks in the future, installing OBSs and cables within grooves dug in the seafloor or by burial will be effective in suppressing such natural vibrations.
\end{abstract}

Keywords: S-net, ETMC, DONET, "N"-shape in the Y/X amplitude spectral ratio, Natural vibration of the pressure vessel, Coupling with the seafloor

\section{Introduction}

After the 2011 Tohoku-Oki earthquake ( $\left.\mathrm{M}_{\mathrm{W}} 9.0\right)$ and tsunami, which resulted in at least 18,000 dead and missing people, National Research Institute for Earth Science and Disaster Resilience (NIED) installed the Seafloor Observation Network for Earthquakes and Tsunamis (S-net) along the Japan Trench (e.g., Kanazawa et al. 2016). S-net was designed to detect tsunamis and earthquakes

\footnotetext{
*Correspondence: sawa@bosai.go.jp

${ }^{1}$ National Research Institute for Earth Science and Disaster Resilience, 3-1

Tennodai, Tsukuba, Ibaraki 305-0006, Japan

Full list of author information is available at the end of the article
}

much earlier than existing seismic networks. It was also expected to provide valuable data that may advance marine seismology. The S-net records have already produced new discoveries, such as non-volcanic tremors (e.g., Tanaka et al. 2019; Nishikawa et al. 2019) and small tsunamis (e.g., Kubota et al. 2020) that have not been detected by land or coastal observations.

Since ocean bottom seismic observations are different to land seismic observations in many ways, problems specific to ocean bottom observations should be shared as much as possible. For example, Takagi et al. (2019) measured the orientation of three-component 
seismometers in S-net using DC offsets and far-field waveforms from accelerograms. This showed that, unlike land seismic observations, the orientations of S-net seismograms require correction with respect not only to azimuth but also the tilt and rotation angles of the installed pressure vessel. Nakamura and Hayashimoto (2019) detected a significant change in the DC offset before and after strong ground motion in in-line-type OBSs installed at Sanriku-Oki, Japan. This change was interpreted to reflect rotation of the pressure vessel due to decoupling from the ocean bottom during the strong ground motion. Using seismograms affected by such rotation may lead to an overestimation of earthquake magnitude.

These issues are related to the asymmetric shape of the observation system that is specific to in-line-type OBS networks, and insufficient coupling with the seafloor. Given these factors, the two horizontal components from inline type OBSs may respond to incident waves differently. Previous studies have examined this issue by polarization analysis of artificial shots (e.g., Woje et al. 2002; Bagaini and Muyzert 2004; Landschulze and Mjelde 2014). However, artificial shots are too expensive to be applied to a largescale seismograph network such as S-net, and can also have a negative impact on the environment. Noise records can also be used to evaluate the response of the two horizontal components (e.g., Landschulze and Mjelde 2016). However, the noise wavefield itself typically has polarity in the oscillation direction due to contamination of various types of waves such as Rayleigh waves and T-waves (e.g., Ardhuin et al. 2019). Therefore, it is difficult to resolve responses specific to installation from the natural properties of noise.

In this study, we examined the difference between the amplitude spectra of two horizontal components recorded by OBSs using S-coda waves in seismograms. Figure 1 shows examples of amplitude spectral ratios of an S-coda wave amongst the three components $(\mathrm{Y} / \mathrm{X}$, $\mathrm{X} / \mathrm{U}$, and $\mathrm{Y} / \mathrm{U}$ ) observed at S-net stations N.S1N01 and N.S6N14. Hereafter, the X, Y, and U components correspond to directions along the cable axis (horizontal), perpendicular to the cable axis (horizontal), and vertical, respectively. For N.S1N01 (Fig. 1b), the amplitude spectral ratios of $\mathrm{X} / \mathrm{U}$ and $\mathrm{Y} / \mathrm{U}$ are similar and $\mathrm{Y} / \mathrm{X}$ is close to unity from 0 to $30 \mathrm{~Hz}$. This behavior is typical for an $\mathrm{S}$-coda wave because it is composed of multiply scattered S-waves and the oscillation direction is, in theory, horizontally isotropic (e.g., Sato et al. 2012) unless strong horizontal anisotropy exists below the seafloor. However, for N.S6N14 (Fig. 1d), the amplitude spectral ratios of $\mathrm{X} / \mathrm{U}$ and $\mathrm{Y} / \mathrm{U}$ show peaks at different frequencies (i.e., 18 and $7 \mathrm{~Hz}$ ), and $\mathrm{Y} / \mathrm{X}$ shows a notch and peak at these frequencies, respectively. As a result, the $\mathrm{Y} / \mathrm{X}$ amplitude spectral ratio shows an " $\mathrm{N}$ "-shape. In fact, such an " $\mathrm{N}$ "shaped Y/X amplitude spectral ratio has been observed from many S-net OBSs. Related observation was reported by Hayashimoto et al. (2016) from in-line-type OBSs installed at Kushiro-Oki, Japan, where the spectral amplitude of the $\mathrm{X}$-component is much larger than the Y-component at frequencies of $>10 \mathrm{~Hz}$.

We examined the $\mathrm{Y} / \mathrm{X}$ amplitude spectral ratios of $\mathrm{S}$-coda waves from S-net seismograms, and also those from OBSs of the Earthquake and Tsunami Monitoring Cable (ETMC) installed along the Sagami Trough and the Dense Oceanfloor Network system for Earthquakes and Tsunamis (DONET) installed close to the Nankai Trough. Since these three types of OBS network are different in many aspects, they enable us to identify the cause of the " $\mathrm{N}$ "-shaped Y/X amplitude spectral ratio.

\section{OBS networks of S-net, ETMC, and DONET}

There are two main types of permanent ocean bottom seismic observatory system deployed around the world. One is composed of geophysical sensors integrated into a submarine cable with a power feed and optical fiber, which is sometimes referred to as an "in-line system" (e.g., Fujiwara et al. 2010). Stations can be deployed rapidly and for low initial cost by installing the cable into ocean bottom areas from a cable ship without using a remotely operated vehicle (ROV). The other type is a system composed of sensors and science nodes (or junction boxes) that are physically connected or disconnected to a cable by a ROV. This system enables expansion of observatory areas by connecting a new cable to interfaces at the nodes and by adding sensors. Hereafter, we refer to this as the "node-type" system following Fujiwara et al. (2010). The ETMC (Eguchi et al. 1998) and S-net (Kanazawa et al. 2016; Mochizuki et al. 2016; Uehira et al. 2016) deployed in eastern Japan are classified as the former system, whereas DONET (Kaneda et al. 2015; Kawaguchi et al. 2015) in southwestern Japan is the latter system.

\section{S-net}

S-net comprises 150 ocean-bottom stations and optical fiber cables installed along the Japan Trench (Fig. 2a). The stations and cables installed at water depths shallower than $1500 \mathrm{~m}$ (Fig. 2a) are mostly installed within grooves dug to at least $1 \mathrm{~m}$ below the seafloor to avoid the risk of cable damage due to fishing (Kanazawa et al. 2016). Each station is equipped with a velocity seismometer (OMNI-2400; OYO-GeoSpace), accelerometers, and pressure gauges to monitor earthquakes and tsunamis. All sensors at each station are housed in a cylindrical pressure vessel that is placed sideways on the seafloor (long-axis lies in the horizontal plane). Both ends of the pressure vessel are connected to optical fiber cables. Ground motion and water pressure records are transmitted to land station via the cables. 


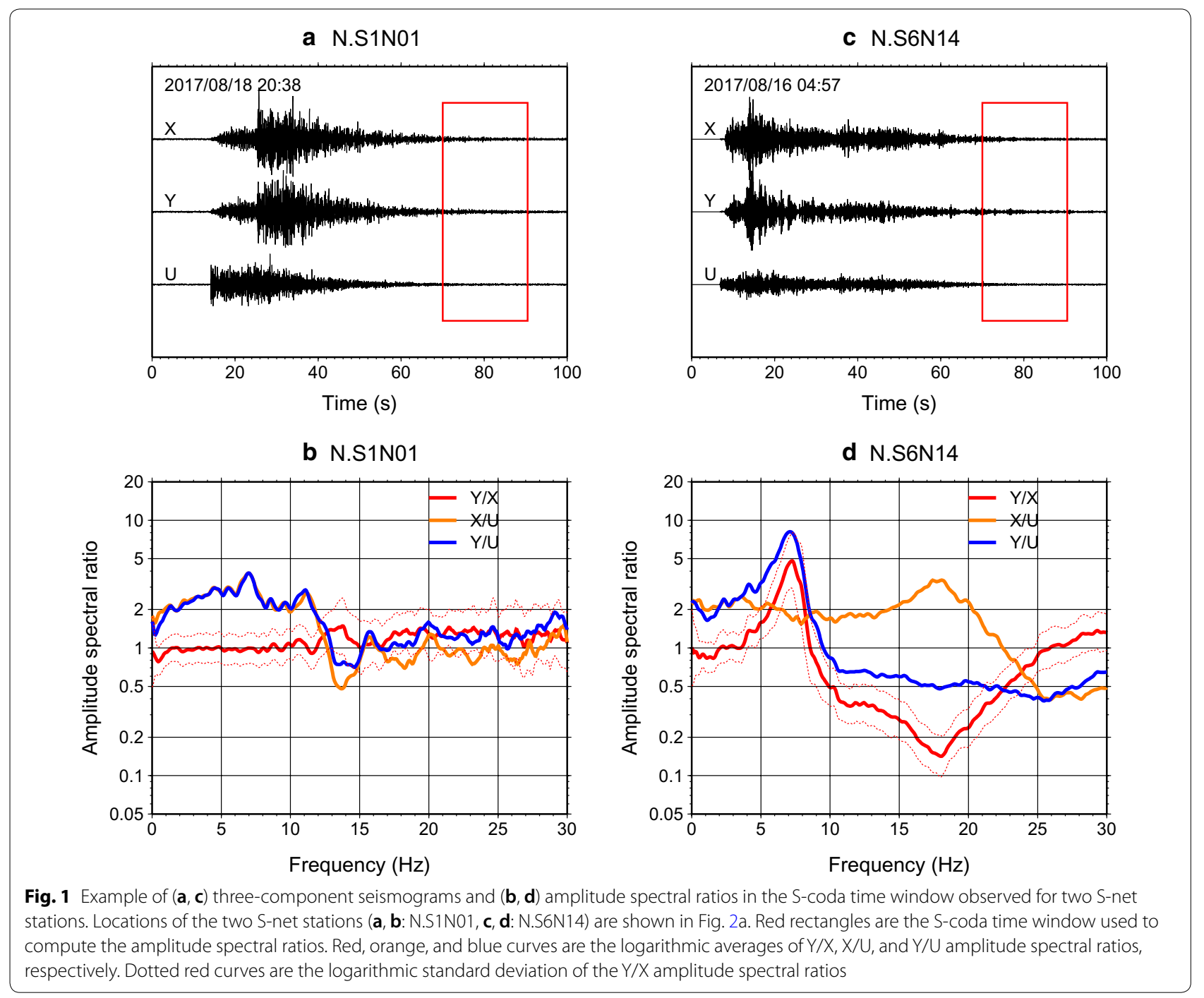

We used velocity seismometers in this study, which have a natural frequency of $15 \mathrm{~Hz}$, and electrical signal is digitized at $100 \mathrm{~Hz}$ sampling.

To restore $\mathrm{X}, \mathrm{Y}$, and $\mathrm{U}$ components from the original three components, we used the tilt and rotation angles of the pressure vessels determined by Takagi et al. (2019). Although Takagi et al. (2019) referred to the restored components as X, Y, and U, we use X, Y, and $\mathrm{U}$, respectively, in this study.

The seismograms of S-net have been openly available online from 15 August 2016, apart for records of segment 6 (S6; mostly installed on the outer rise) from 13 April 2017. Kanazawa et al. (2016) described the S-net system in detail.

\section{ETMC}

The ETMC seismic network comprises six ocean-bottom stations and optical fiber cables installed along the
Sagami Trough (Fig. 2b). Like the S-net system, each ETMC seismic station consists of a velocity seismometer and an accelerometer (both produced by Akashi Co.). Both sensors are housed in a cylindrical pressure vessel that is placed sideways on the seafloor. We used velocity seismometers in this study that have a flat frequency response from 1 to $30 \mathrm{~Hz}$, and electrical signal is digitized at $100 \mathrm{~Hz}$ sampling. Unlike the S-net system, each seismometer is maintained horizontally by a gimbal mechanism. Therefore, we did not correct the orientations of the $\mathrm{X}, \mathrm{Y}$, and $\mathrm{U}$ components. Each pressure vessel is equipped with a "coupling cover" to improve coupling with the seafloor. None of the stations are buried beneath the seafloor.

The seismograms of ETMC have been openly available online from 1 April 2004. Eguchi et al. (1998) described the details of the ETMC system. 


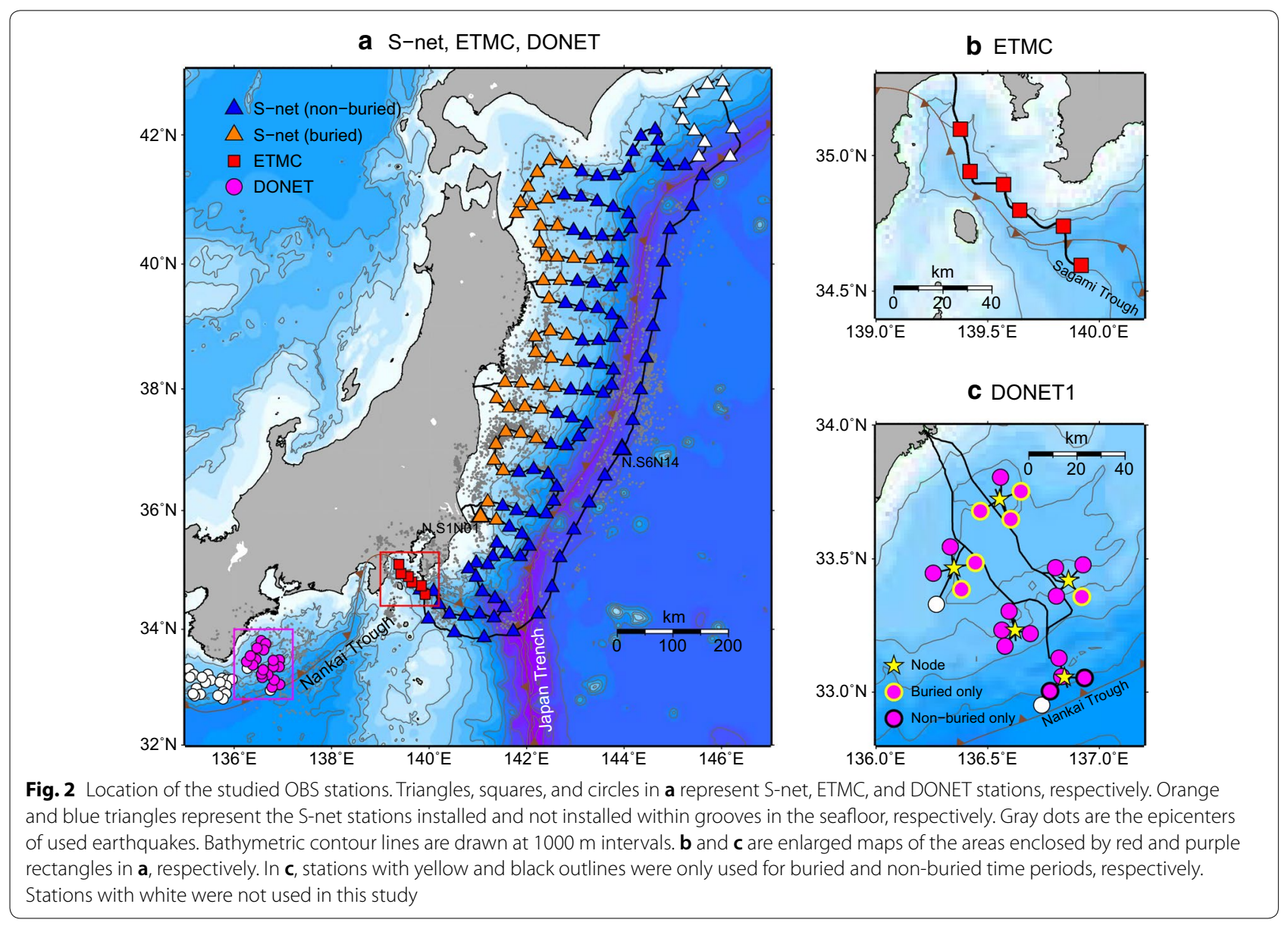

\section{DONET}

DONET1 (eastern segment) and DONET2 (western segment) comprise 22 and 29 ocean-bottom stations, respectively, which are installed close to the Nankai Trough (Fig. 2a and c). Each DONET station is equipped with an accelerometer, a broadband seismometer (CMG-3 T; Güralp), a hydrophone, a differential pressure gauge, a water-pressure gauge, and a thermometer. These multiple sensors are used to detect not only normal earthquakes, but also slow earthquakes, tsunamis, and even crustal deformation. We used broadband seismometers in this study, which have a flat frequency response from $1 / 360$ to $50 \mathrm{~Hz}$ and electrical signal is digitized at $100 \mathrm{~Hz}$ sampling. Unlike S-net and ETMC, science nodes (Fig. 2c) are connected to the backbone cable, and four or five stations are connected to each science node via an extension cable. All sensors at each station are housed in a cylindrical pressure vessel that is placed upright (long-axis is vertically oriented). Burial of the pressure vessels depends on the site and time period, as summarized in Table 1. Like ETMC, each seismometer is maintained horizontally by a gimbal mechanism.
The seismograms of DONET1 and 2 have been openly available online from July 2011 and March 2016, respectively. Since the background seismicity of the Nankai Trough is relatively low and we could not collect enough number of seismograms for DONET2, we only used DONET1 data in this study. To examine the effects of burial, we analyzed records of non-buried and buried time periods separately (Table 1 ). Figure 2c shows stations used only for non-buried time period, buried time period, and both time periods. Kaneda et al. (2015) and Kawaguchi et al. (2015) described the DONET system in detail.

Table 2 summarizes the specifications of each OBS network that are relevant to this study.

\section{Data and methods}

We used 139, 6, 14, and 18 OBS stations from S-net, ETMC, non-buried DONET1, and buried DONET1, respectively. Based on the Japan Meteorological Agency (JMA) unified hypocenter catalog, we selected earthquakes with both epicentral distances and depths of $<80 \mathrm{~km}$ and magnitudes of 3-6. In total, 40566, 2867, 
Table 1 Burial information for the studied DONET1 stations

\begin{tabular}{llll}
\hline Station code & Burial date & $\begin{array}{l}\text { Non-burial } \\
\text { period used }\end{array}$ & $\begin{array}{l}\text { Burial } \\
\text { period } \\
\text { used }\end{array}$ \\
\hline M.KMA01 & $2013 / 02 / 03$ & 0 & 0 \\
M.KMA02 & $2010 / 10 / 10$ & $\times$ & 0 \\
M.KMA03 & $2011 / 03 / 15$ & $\times$ & 0 \\
M.KMA04 & $2011 / 08 / 02$ & $\times$ & 0 \\
M.KMB05 & $2013 / 02 / 04$ & 0 & 0 \\
M.KMB06 & $2011 / 01 / 10$ & $\times$ & 0 \\
M.KMB07 & $2013 / 02 / 04$ & 0 & 0 \\
M.KMB08 & $2013 / 02 / 05$ & 0 & 0 \\
M.KMC09 & $2013 / 01 / 29$ & 0 & 0 \\
M.KMC10 & Not buried & 0 & $\times$ \\
M.KMC11 & Not buried & 0 & $\times$ \\
M.KMC12 & $2013 / 01 / 27$ & 0 & 0 \\
M.KMD13 & $2013 / 01 / 30$ & 0 & 0 \\
M.KMD14 & $2013 / 01 / 27$ & 0 & 0 \\
M.KMD15 & $2013 / 01 / 30$ & 0 & 0 \\
M.KMD16 & $2013 / 01 / 31$ & 0 & 0 \\
M.KME17 & $2010 / 05 / 29$ & $\times$ & 0 \\
M.KME18 & $2013 / 01 / 31$ & $\times$ & 0 \\
M.KME19 & $2013 / 01 / 26$ & 0 & 0 \\
M.KME20 & $2013 / 01 / 28$ & 0 & 0 \\
\hline
\end{tabular}

552, and 2260 event waveforms were used for S-net, ETMC, non-buried DONET1, and buried DONET1, respectively. At least 10 event waveforms were used for each station.

The time window of S-coda wave begins $70 \mathrm{~s}$ after the origin time and is $20.48 \mathrm{~s}$ (2048 samples) long (Fig. 1a and c). This time window corresponds to the multiple scattering regime, in which the oscillation direction of S-coda wave is considered to be horizontally isotropic (e.g., Sato et al. 2012). Therefore, the amplitude spectra of two horizontal components should be similar for this time window, in theory, unless strong horizontal anisotropy exists in the subsurface and/or installation. To evaluate the signal to noise $(\mathrm{S} / \mathrm{N})$ ratio of the coda amplitude spectra, we also set a noise time window that begins either before the P-wave onset time or $>220 \mathrm{~s}$ after the origin time. By rotating $\mathrm{X}$ and $\mathrm{Y}$ components in a horizontal plane and taking the amplitude spectral ratio for each rotation angle $\theta$, we search for the direction in which the "N"shape forms.

The data processing procedure is as follows.

1. For S-net seismograms, convert the original three components to $X, Y$, and $U$ components following the method of Takagi et al. (2019).

2. Remove the mean.

3. Rotate $X$ and $Y$ components every $10^{\circ}$ in a horizontal plane. We obtained nine pairs of orthogonal horizontal components $U_{X}(\theta)$ and $U_{Y}(\theta)$ (i.e., $\theta$ ranges from $-40^{\circ}$ to $+40^{\circ}$ ).

4. Apply a $2 \%$ cosine taper.

5. Compute the power spectra using the Fast Fourier Transform (FFT).

6. Smooth the power spectra by applying a Hann window 15 times in frequency domain. The bandwidth of this smoothing is approximately $0.5 \mathrm{~Hz}$ (e.g., Ohsaki 1994).

7. Compute the amplitude spectral ratio $\left|U_{Y}(\theta, f) / U_{X}(\theta, f)\right|$.

8. Compute the logarithmic average $A_{Y / X}$ and logarithmic standard deviation $S_{Y / X}$ of the amplitude spectral ratio using all event waveforms recorded at each station as

$$
A_{Y / X}(\theta, f)=10 \frac{\sum_{i} \log \mid \mathrm{U}_{\mathrm{Y}_{\mathrm{i}}}(\theta, \mathrm{f}) / \mathrm{U}_{\mathrm{X}_{\mathrm{i}}(\theta, \mathrm{f}) \mid \mathrm{W}_{\mathrm{i}}(\theta, \mathrm{f})}}{\sum_{i} W_{i}(\theta, f)}
$$

and

$$
S_{Y / X}(\theta, f)=\sqrt{\frac{\sum_{i}\left\{\log \left|\mathrm{U}_{\mathrm{Yi}}(\theta, \mathrm{f}) / \mathrm{U}_{\mathrm{Xi}}(\theta, \mathrm{f})\right|-\log \left[\mathrm{A}_{\mathrm{Y} / \mathrm{X}}(\theta, \mathrm{f})\right]\right\}^{2} W_{i}(\theta, f)}{\sum_{i} W_{i}(\theta, f)}},
$$

\begin{tabular}{|c|c|c|c|}
\hline & S-net & ETMC & DONET \\
\hline Type of observation system & In-line & In-line & Node \\
\hline $\begin{array}{l}\text { Digging around station or buried when } \\
\text { installed }\end{array}$ & $\begin{array}{l}\text { Most stations installed at water depths } \\
\text { of }<1500 \mathrm{~m}\end{array}$ & No & $\begin{array}{l}\text { Dependent on site and } \\
\text { period (Table 1) }\end{array}$ \\
\hline $\begin{array}{l}\text { Mounted equipment to enhance coupling } \\
\text { with seafloor }\end{array}$ & No & Yes & Yes \\
\hline Gimbal system & No & Yes & Yes \\
\hline Used seismic sensor & Velocity seismometer $(15 \mathrm{~Hz})$ & Velocity seismometer (1 Hz) & Broadband seismometer \\
\hline
\end{tabular}

Table 2 Specifications of S-net, ETMC, and DONET relevant to this study 
respectively, where $i$ is the number of event waveforms. The weight function $W$ is defined as

$$
\begin{gathered}
W_{i}(\theta, f)=\left\{\begin{array}{c}
1-2 F_{i}(\theta, f) \text { if } F_{i}(\theta, f)<0.495 \\
0.01 \text { if } F_{i}(\theta, f) \geq 0.495
\end{array}\right. \\
F_{i}(\theta, f)=\left|\frac{n_{X i}(\theta, f)}{U_{X i}(\theta, f)}\right|^{2}+\left|\frac{n_{Y i}(\theta, f)}{U_{Y i}(\theta, f)}\right|^{2}
\end{gathered}
$$

where $n_{X}$ and $n_{Y}$ represent the orthogonal two components of the noise spectra. Equation (3) indicates $W$ is close to unity if amplitude of the coda spectra is much larger than that of the noise spectra. As the amplitude of the coda spectra approaches the noise level, $W$ decreases and approaches almost zero.

9. To examine the horizontal anisotropy of amplitude spectra, two indices defined by

$$
D_{1}(\theta)=\frac{1}{J} \sum_{j=1}^{J}\left|\log \left[\mathrm{A}_{\mathrm{Y} / \mathrm{X}}\left(\theta, \mathrm{f}_{\mathrm{j}}\right)\right]\right|
$$

and

$$
D_{2}(\theta)=\frac{1}{J} \sum_{j=1}^{J} S_{Y / X}\left(\theta, f_{j}\right)
$$

are introduced. $D_{1}$ represents the degree of dissimilarity between the two orthogonal components, and $D_{2}$ represents the frequency average of the logarithmic standard deviation. The evaluated frequency range is $f_{1}=3 \mathrm{~Hz}$ and $f_{\mathrm{J}}=25 \mathrm{~Hz}$, within which the S-coda wave is considered to be composed of multiply scattered S-waves (e.g., Sato et al. 2012). $D_{1}$ is equal to zero if $A_{Y / X}$ is unity within the target frequency range and increases as $A_{Y / X}$ deviates more from unity. This deviation becomes statistically more significant as $D_{1} / D_{2}$ increases.

\section{Results}

\section{S-net stations}

The "N"-shaped non-unity curve of $A_{Y / X}$ (Fig. 1d) indicates that the oscillation direction is not horizontally isotropic. Two possibilities can explain this anisotropy: one is contamination by a non-isotropic wavefield, such as by Rayleigh-waves and/or T-waves, and the other is strong horizontal anisotropy in the subsurface and/or installation. We confirmed the former is not likely because the "N"-shape appears even if we use only the earthquakes located near $45^{\circ}$ back azimuth with respect to the $\mathrm{X}$ and $Y$ axes. See Appendix for detail of this confirmation.

Figure 3 shows the $\theta$ dependence of $A_{Y / X}, D_{1}$, and $D_{2}$ at station N.S6N14. Note that the $\theta$ dependence of $D_{1}$ and $D_{2}$ has a $90^{\circ}$ periodicity. The "N"-shaped amplitude spectral ratio is observed most clearly at $\theta=0^{\circ}$ (i.e., pairing of $\mathrm{X}$ and $\mathrm{Y}$ components). As expected from this clear "N"-shape, $D_{1}$ has the largest value at $\theta=0^{\circ}$ and is much larger than $D_{2}$.

We refer to the $\theta$ that gives the maximum $D_{1}$ as $\theta_{\max }$, and to corresponding $D_{1}$ and $D_{2}$ values as $D_{1 \max }=D_{1}\left(\theta_{\max }\right)$ and $D_{2 \max }=D_{2}\left(\theta_{\max }\right)$, respectively. Figure 4a shows a plot of $\theta_{\max }$ versus $D_{1 \max }$ and $D_{2 \max }$ for all the used S-net stations. Most of the large and statistically significant $D_{1 \max }$ values are observed at $\theta_{\max }=0^{\circ}$. This result indicates that strong horizontal anisotropy of amplitude spectra tends to appear for the pair of
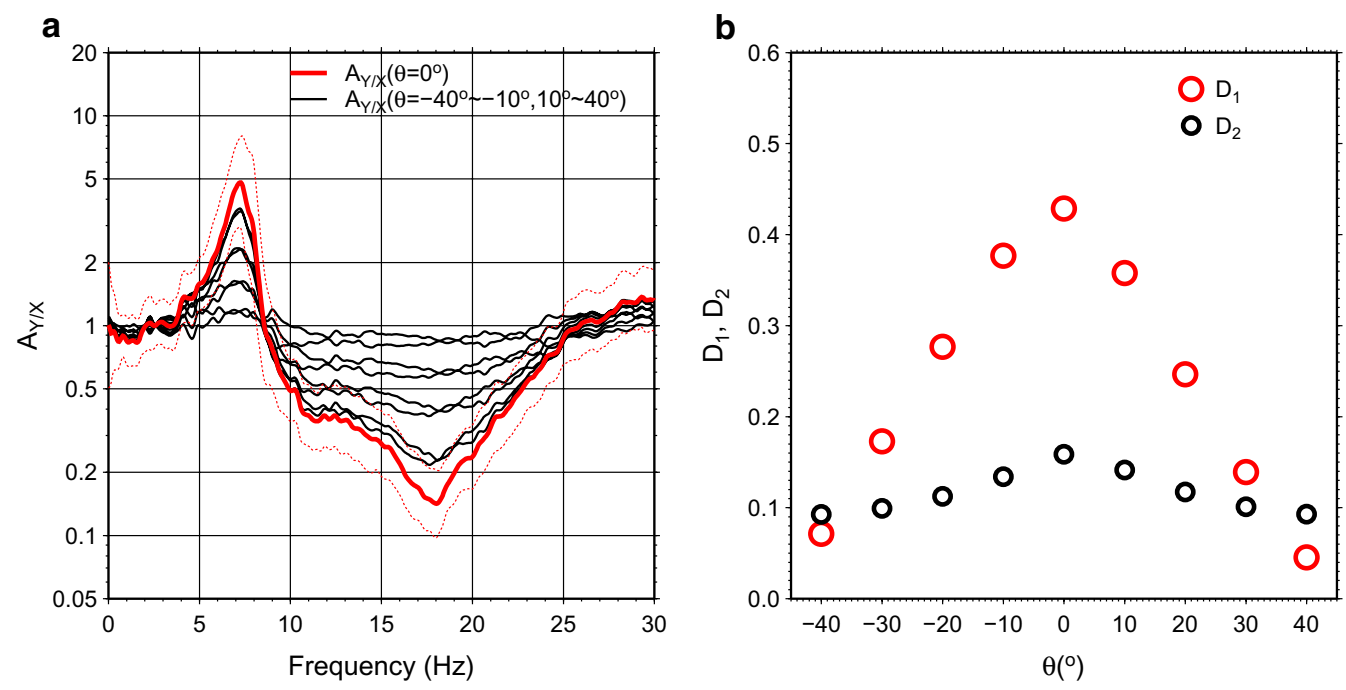

Fig. 3 Rotation angle $\theta$ dependence of (a) average $Y / X$ amplitude spectral ratio and (b) $D_{1}$ (red circles) and $D_{2}$ (black circles) values obtained for station N.S6N14. Red and thin black curves in a represent amplitude spectral ratios for $\theta=0^{\circ}$ and other rotation angles $\left(-40^{\circ}--10^{\circ}, 10^{\circ}-40^{\circ}\right)$, respectively. Red dotted curves are logarithmic standard deviation of the $\mathrm{Y} / \mathrm{X}$ amplitude spectral ratio for $\theta=0^{\circ}$ 

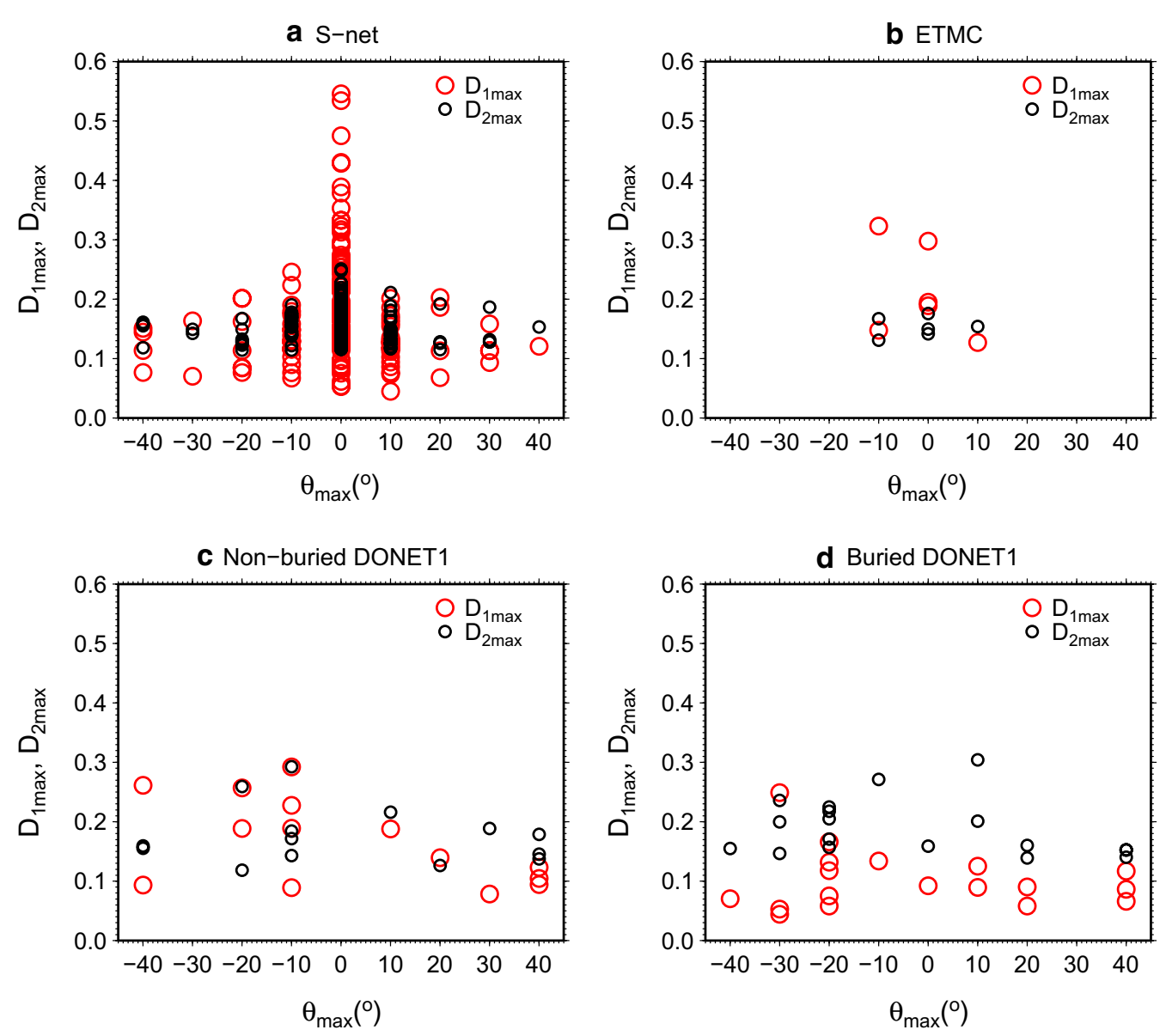

Fig. 4 Plot of $\theta_{\max }$ versus $D_{1 \max }$ (red circles) and $D_{2 \max }$ (black circles) for (a) S-net, b ETMC, c non-buried DONET1, and $\mathbf{d}$ buried DONET1 stations

along-cable (X) and perpendicular-to-cable (Y) components. Since the orientation of the cable is not related to topography or geological structure, the observed horizontal anisotropy of amplitude spectra is unlikely to arise from subsurface structures; instead, it reflects the installation of the pressure vessel at each station.

In Fig. 5a, we map $D_{1 \max }$ using a color scale for all the used S-net stations. Stations with large $D_{1 \max }$ are located in relatively offshore regions, although not all offshore stations have large $D_{1 \max }$. On the other hand, most of the near coast stations installed within grooves (orange triangles in Fig. 2a) have relatively small $D_{1 \max }$ values.

Figure 6a shows a plot of the installed water depth versus $D_{1 \max }$ and $D_{2 \max }$ for all the used S-net stations. $D_{1 \max }$ is smaller than $D_{2 \max }$ for most of S-net stations installed at water depths shallower than $1500 \mathrm{~m}$ (vertical dotted line), while a significant number of stations at water depths deeper than $1500 \mathrm{~m}$ have much larger $D_{1 \max }$. This depth dependence occurs abruptly at the threshold depth of $1500 \mathrm{~m}$. As described in Table 2, most of S-net stations at water depths shallower than $1500 \mathrm{~m}$ are installed within grooves dug in the seafloor. Therefore, this result indicates installation within a groove is related to the suppression of horizontal anisotropy of amplitude spectra.

Figure 7 shows $A_{Y / X}$ curves of 12 selected S-net stations with different $D_{1 \max }$ values amongst those installed at water depths deeper than $1500 \mathrm{~m}$. Most stations form an "N"-shaped Y/X amplitude spectral ratio, although it becomes less obvious as $D_{1 \max }$ decreases. The peak and notch tend to appear at $5-9 \mathrm{~Hz}$ and $10-23 \mathrm{~Hz}$, respectively. Because the instrumental responses are the same for the $\mathrm{X}$ and $\mathrm{Y}$ components in the specification, we think the common "N"-shape at different sites must be due to the installation situation of each OBS.

Figure 8 shows $A_{Y / X}$ curves of $12 \mathrm{~S}$-net stations with the largest $D_{1 \max }$ amongst those installed at water depths shallower than $1500 \mathrm{~m}$. All stations except for N.S1N08 do not form an "N"-shape even for those having relatively large $D_{1 \max }$. Actually, N.S1N08 station is not installed within a groove although it is installed at water depths shallower than $1500 \mathrm{~m}$ (Uehira, personal communication). In comparison with Fig. 7, we think the S-net 


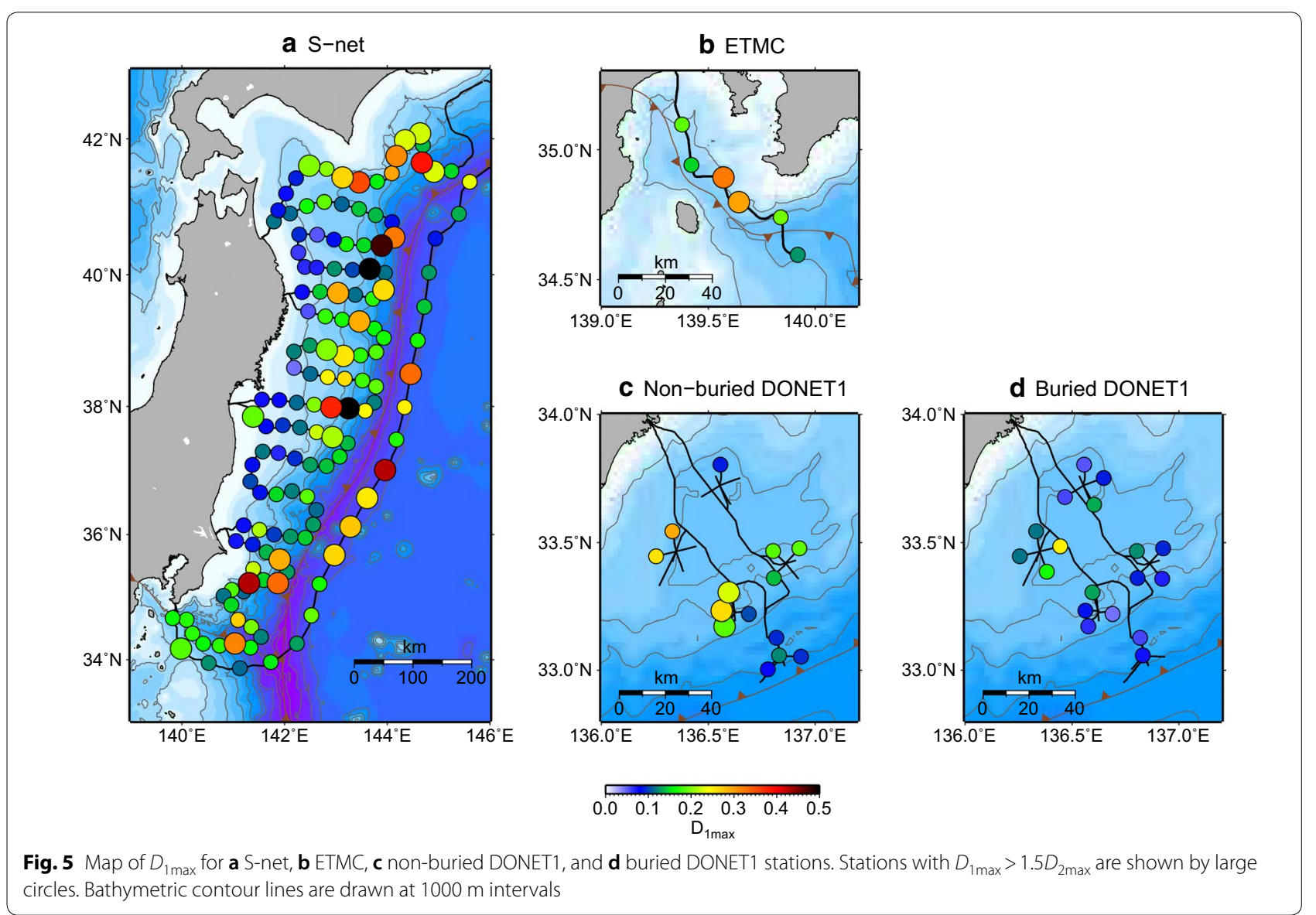

stations installed within grooves are not characterized by the " $\mathrm{N}$ "-shape regardless the value of $D_{1 \max }$.

\section{ETMC stations}

ETMC is an in-line-type ocean bottom observation network like S-net, but it is different from S-net in some aspects (Table 2). Figures $4 \mathrm{~b}, 5 \mathrm{~b}$, and $6 \mathrm{~b}$ correspond to Figs. 4a, 5a, and 6a, respectively, but for ETMC stations. Two of six ETMC stations have $D_{1 \max }$ significantly larger than $D_{2 \max }$ and $\theta_{\max }$ values of all six stations are within $-10^{\circ}$ and $10^{\circ}$ (Fig. 4b). This result indicates that strong horizontal anisotropy of amplitude spectra tends to appear for pair of the along-cable $(\mathrm{X})$ and perpendicularto-cable $(\mathrm{Y})$ components, as for S-net. However, unlike $\mathrm{S}$-net, stations with relatively large $D_{1 \max }$ are located at relatively shallow water depths (Fig. 6b).

Figure 9 shows $A_{Y / X}$ curves of all six ETMC stations. Not only the two stations with large $D_{1 \max }$ (N.ST3H and N.ST4H) but also some stations with smaller $D_{1 \max }$ form "N"-shape, although those for the latter are less obvious. Unlike S-net, each ETMC station is equipped with a coupling cover to avoid rotation and a gimbal system to maintain a horizontal state. However, considering the similarity of the "N"-shape observed for both ETMC and non-buried S-net stations, the coupling cover and gimbal system do not appear to efficiently suppress the "N"-shape of the Y/X amplitude spectral ratio. The peak and notch frequencies are observed at $6-13 \mathrm{~Hz}$ and $14-23 \mathrm{~Hz}$, which are slightly higher than those of S-net in average.

\section{DONET1 stations}

Figures 4c, 5c, and $6 c$ correspond to Figs. 4a, 5a, and $6 a$, respectively, but for non-buried DONET1 stations. Unlike S-net and ETMC, $\theta_{\max }$ values are distributed relatively uniformly (Fig. 4c). Figures $4 \mathrm{~d}, 5 \mathrm{~d}$, and $6 \mathrm{~d}$ correspond to Figs. 4a, 5a, and 6a, respectively, but for buried DONET1 stations. $D_{1 \max }$ values of the buried DONET1 stations are generally smaller than those of non-buried DONET1 stations (Fig. $5 \mathrm{~d}$ ), and are smaller than $D_{2 \max }$ (Fig. 4d). Like ETMC, stations with relatively large $D_{1 \max }$ are located at relatively shallow water depths (Figs. 6c and d).

Figure 10 shows $A_{Y / X}$ curves of the six DONET1 stations with the largest $D_{1 \max }$ in the non-buried time 

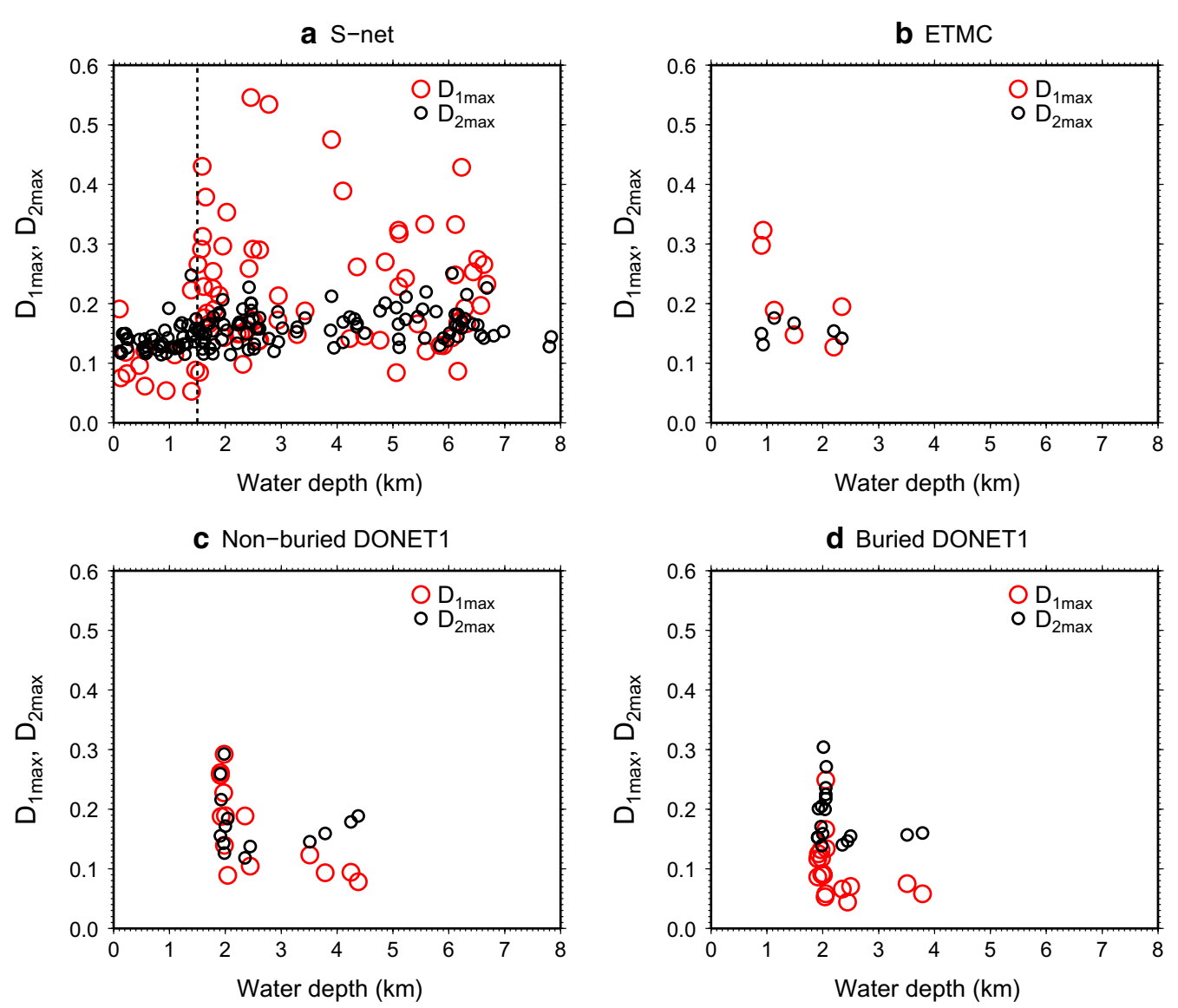

Fig. 6 Plot of water depth versus $D_{1 \max }$ (red circles) and $D_{2 \max }$ (black circles) for a S-net, b ETMC, c non-buried DONET1, and d buried DONET1 stations. The vertical dotted line in a represents a water depth of $1500 \mathrm{~m}$, below which S-net stations were mostly installed within grooves dug in the seafloor

period (red). In each subfigure, we also show the $A_{Y / X}$ curves obtained during the buried time period (blue) at the same station. The $A_{Y / X}$ curves of DONET1 show greater fluctuations than those of S-net and ETMC because the number of used event waveforms is much smaller than the other two OBS networks. The $A_{Y / X}$ curves obtained in the buried time period are closer to unity as compared with those in the non-buried time period. This indicates burial is effective in suppressing differences in the $\mathrm{X}$ and $\mathrm{Y}$ components.

Regardless of whether buried or non-buried, the "N"shape is not formed at all DONET1 stations. Unlike S-net and ETMC, the cylindrical pressure vessels of DONET are placed upright and have no directionality in a horizontal plane. We consider this is the reason why "N"-shape is not formed for DONET1 stations even in the non-buried time period. As such, the "N"shape is likely to be specific to in-line-type OBSs whose pressure vessel is placed sideways on the seafloor.
Based on the survey results targeting the three OBS networks, we hypothesize that the cause of the " $\mathrm{N}$ "shaped Y/X amplitude spectral ratios observed at inline-type stations is natural vibration of an insufficiently coupled pressure vessel. Although the water depth may be related to non-unity of the $D_{1 \max }$ value, it may not be related to emergence of the " $N$ "-shape, and we neglect this effect in further discussion.

\section{Discussion}

Natural vibration model

To explore the natural vibration model and reproduce the observed "N"-shaped Y/X amplitude spectral ratio, we considered two main sources that excite vibrations in the pressure vessel, as shown schematically in Fig. 11.

One source is incident $\mathrm{S}$-waves $\left(S_{X}\right.$ and $\left.S_{Y}\right)$ affecting the coupling zone between the pressure vessel and the seafloor. We suppose that amplitude of the incident $\mathrm{S}$-wave is 

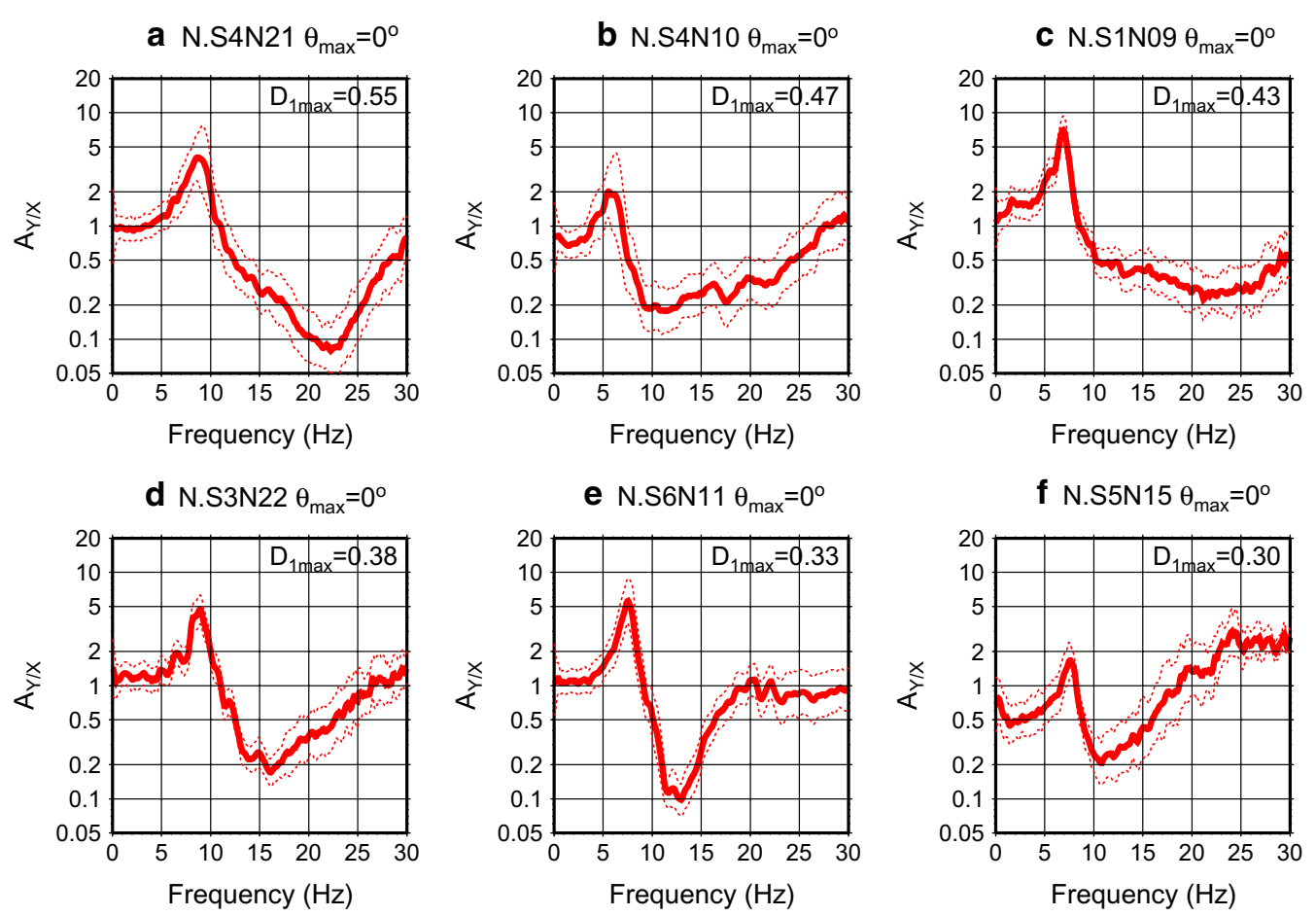

f N.S5N15 $\theta_{\max }=0^{\circ}$
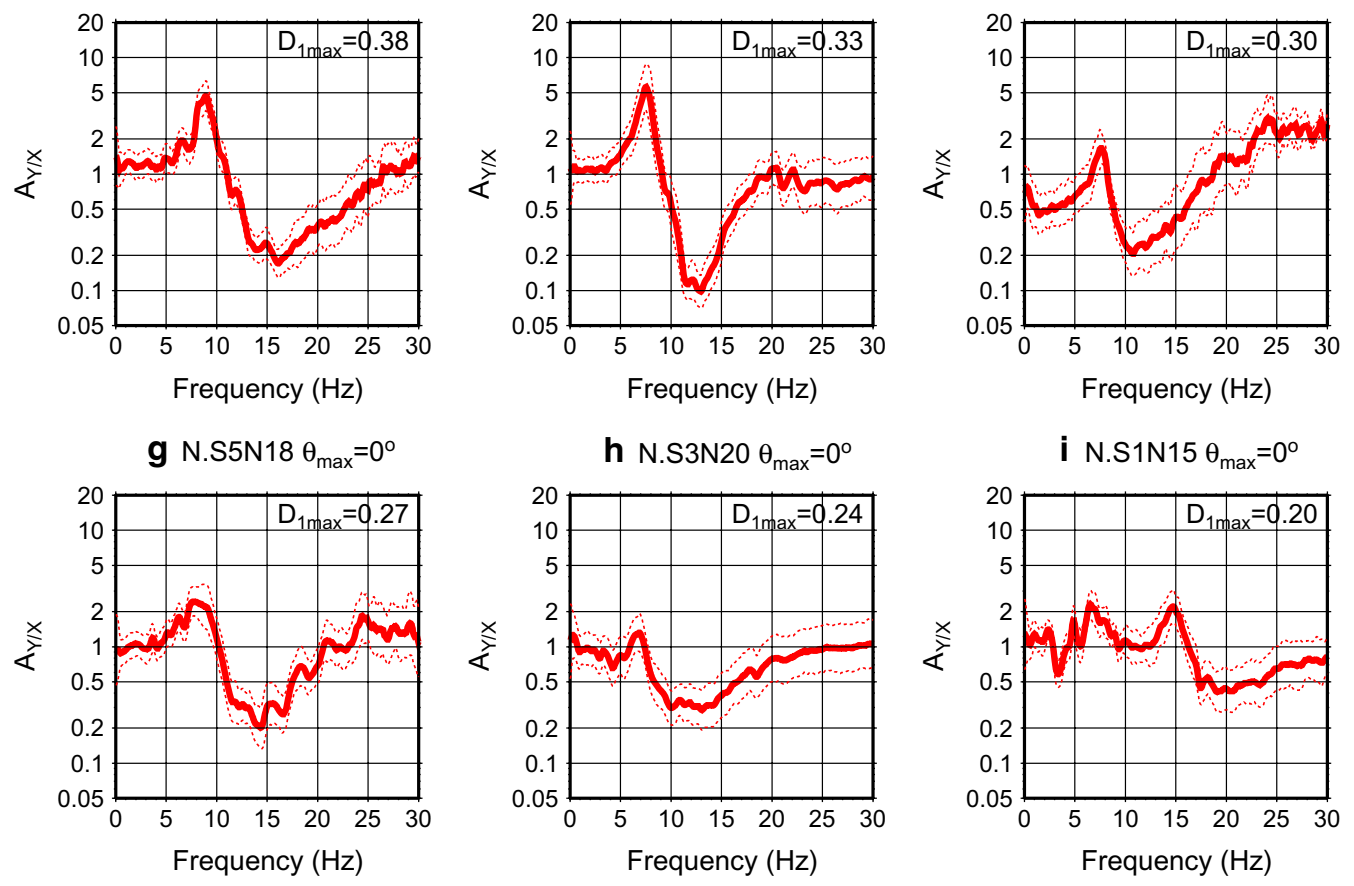

j N.S6N13 $\theta_{\max }=0^{\circ}$
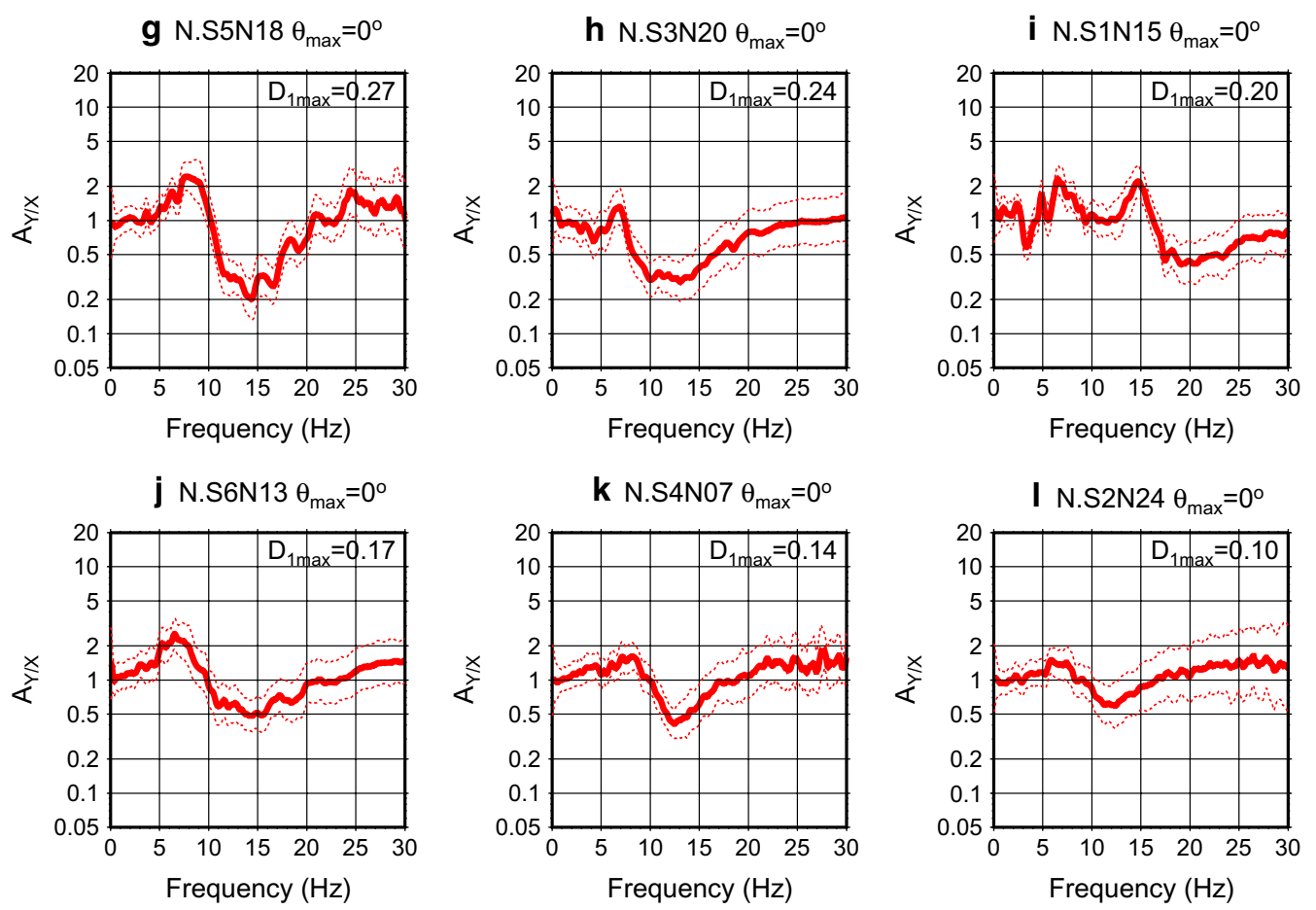

Fig. 7 Average $Y / X$ amplitude spectral ratio (solid red curves) and logarithmic standard deviation (dotted red curves) at $\theta=\theta_{\max }{ }^{\circ}$ obtained for 12 selected S-net stations with different $D_{1 \max }$ amongst those installed at water depths deeper than $1500 \mathrm{~m}$. The $\theta_{\max }$ and $D_{1 \max }$ values for each station are written at the top and inside of each subfigure, respectively 

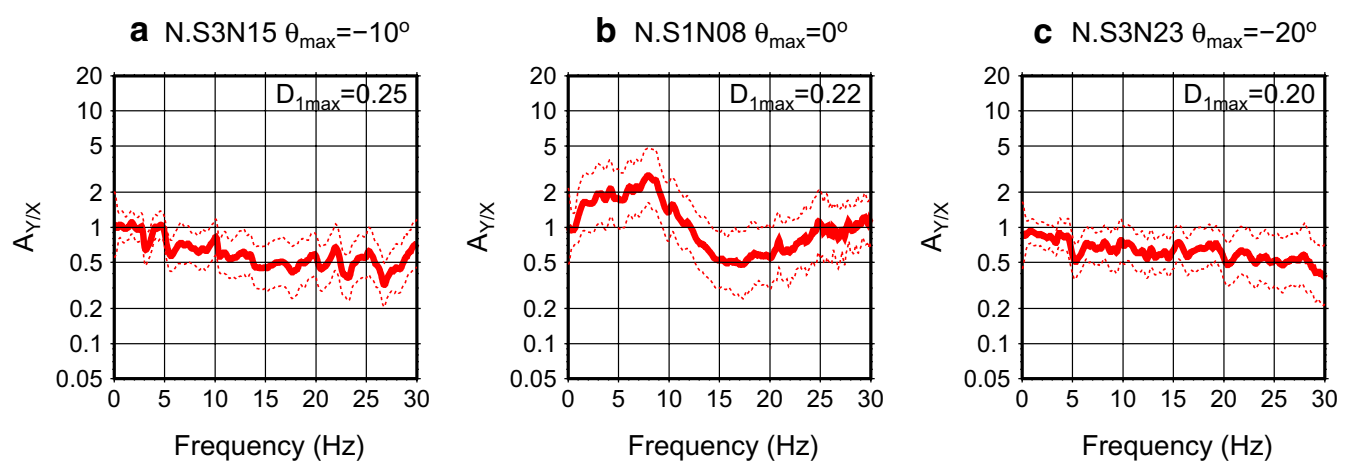

d N.S5N19 $\theta_{\text {max }}=20^{\circ}$

e N.S3N10 $\theta_{\max }=10^{\circ}$

f N.S5N20 $\theta_{\max }=-20^{\circ}$
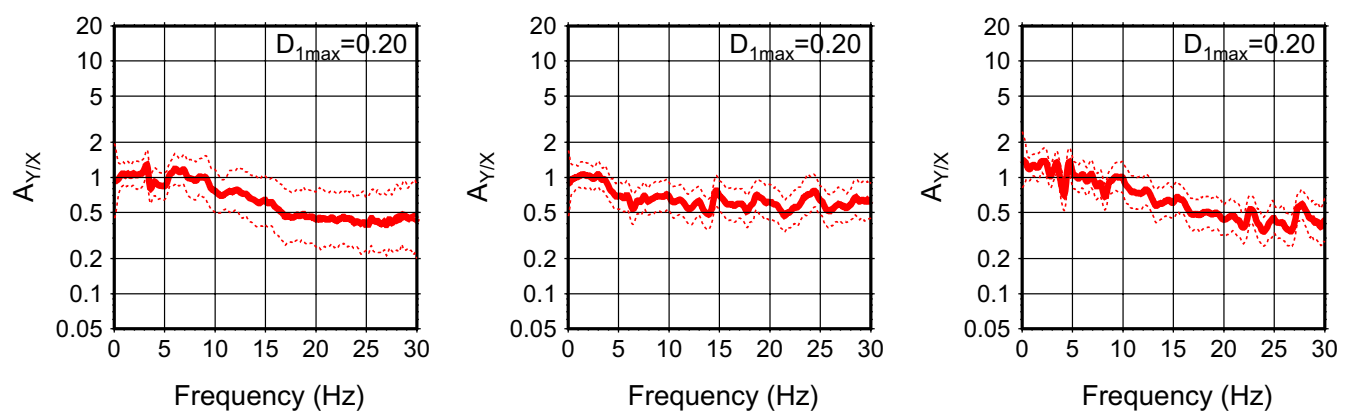

g N.S2N01 $\theta_{\max }=0^{\circ}$

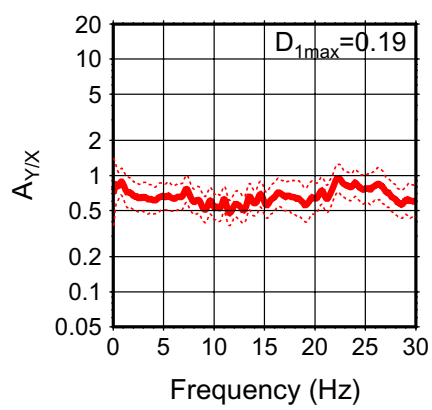

h N.S6N24 $\theta_{\max }=20^{\circ}$

i N.S4N03 $\theta_{\max }=-30^{\circ}$
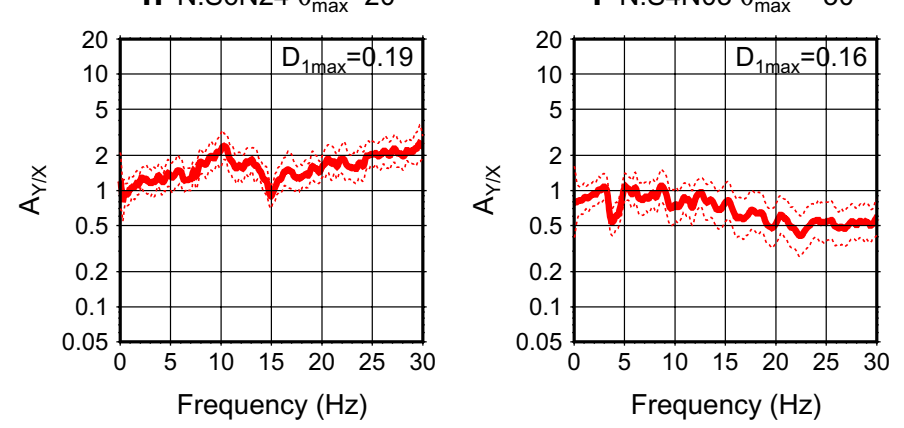

j N.S4N27 $\theta_{\max }=-40^{\circ}$
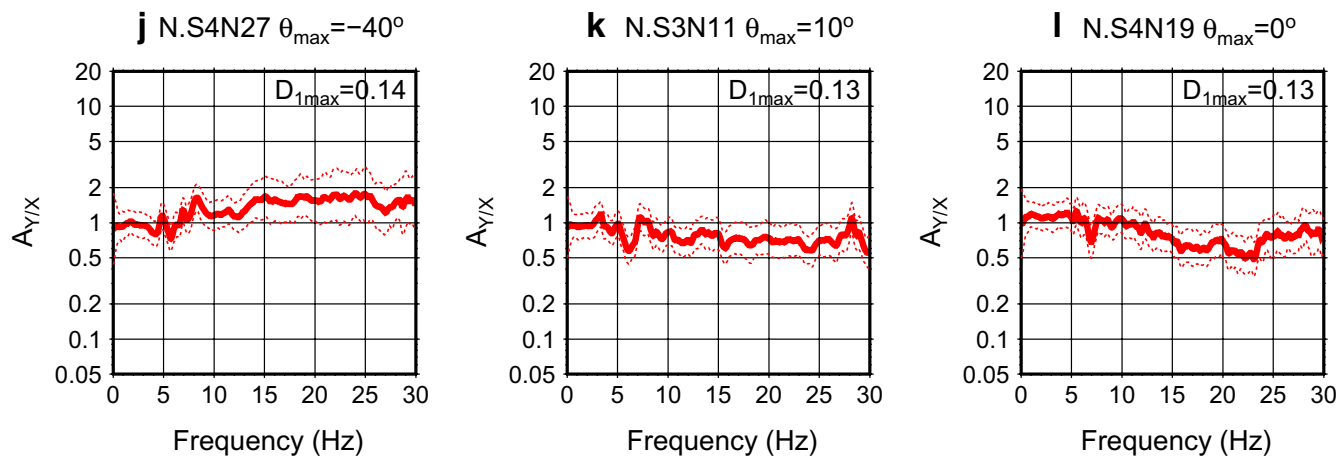

Fig. 8 Average $Y / X$ amplitude spectral ratio (solid red curves) and logarithmic standard deviation (dotted red curves) at $\theta=\theta_{\max }{ }^{\circ}$ obtained for the $12 \mathrm{~S}$-net stations with the largest $D_{1 \text { max }}$ amongst those installed at water depths shallower than $1500 \mathrm{~m}$. The $\theta_{\max }$ and $D_{1 \max }$ values for each station are written at the top and inside of each subfigure, respectively 

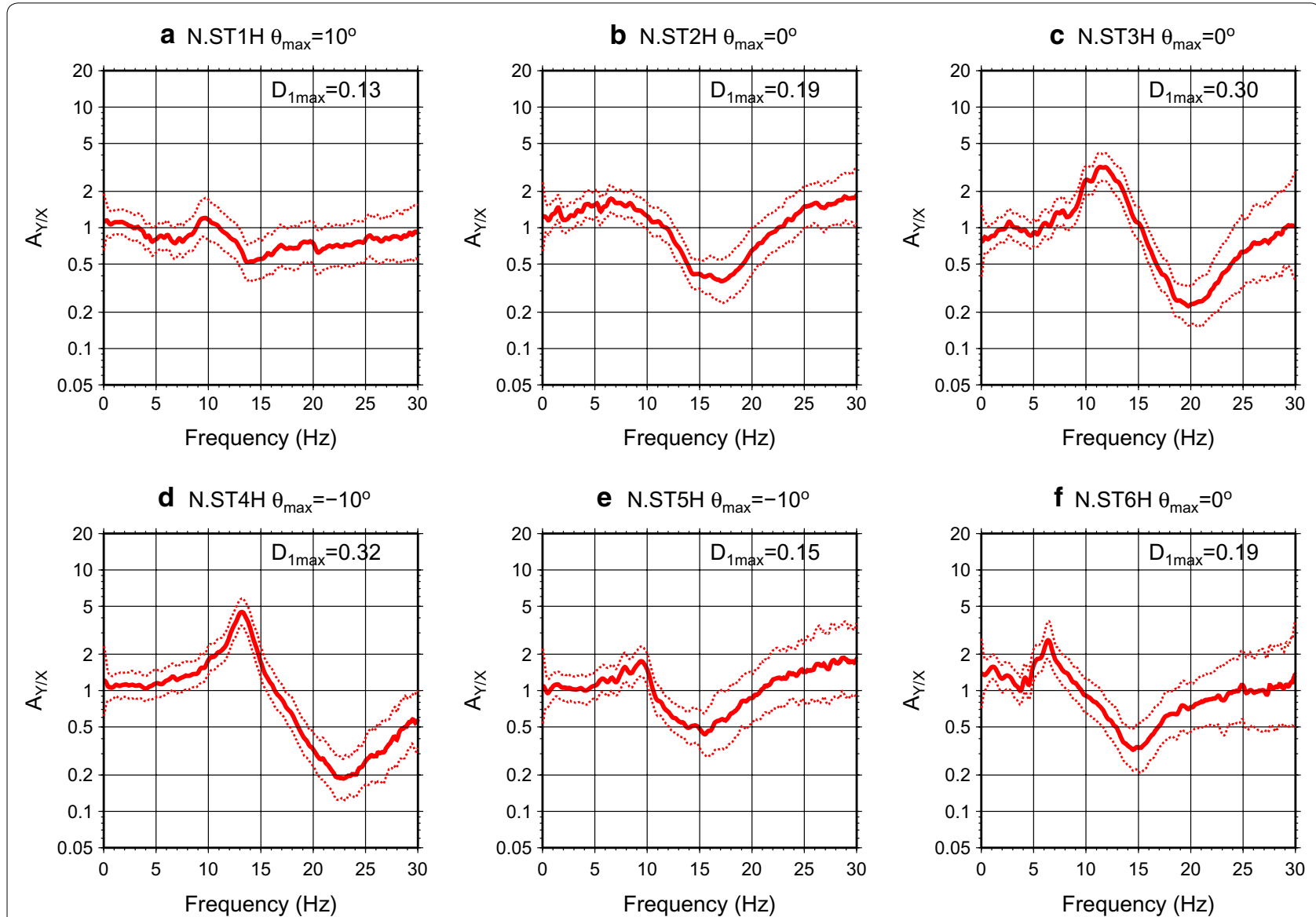

Fig. 9 Average $Y / X$ amplitude spectral ratio (solid red curves) and logarithmic standard deviation (dotted red curves) at $\theta=\theta_{\max }{ }^{\circ}$ obtained for six ETMC stations. The $\theta_{\max }$ and $D_{1 \max }$ values for each station are written at the top and inside of each subfigure, respectively

horizontally isotropic in S-coda time window and regard that $\left|S_{X}(f)\right|=\left|S_{Y}(f)\right|$. If coupling between the pressure vessel and seafloor is sufficient, the incident wave is recorded as is. As the coupling decreases, the proportion of the wave amplitude that can pass through the coupling zone decreases. We denote this proportion as the coupling factor $c$, and assume a common $c$ value for the $\mathrm{X}$ and $\mathrm{Y}$ components for simplicity.

The other source is guided waves (longitudinal $L_{X}$ and transverse $T_{Y}$ ) that propagate in the pressure vessel and cables. We suppose that the guided waves are excited by conversion of the incident $\mathrm{S}$-wave. We assume the relationship given by

$$
\left|\frac{L_{X}(f)}{S_{X}(f)}\right|=\left|\frac{T_{Y}(f)}{S_{Y}(f)}\right|=r
$$

where $r$ is the efficiency of conversion. We assume a common $r$ value for the $\mathrm{X}$ and $\mathrm{Y}$ components for simplicity. Natural vibrations are excited when guided waves are incident on the pressure vessel via the two cable connections at both ends of the pressure vessel. The amplitude response functions of the natural vibrations $G_{X}$ and $G_{Y}$ with respect to the longitudinal and transverse guided waves are approximated by

$$
G_{X}(f)=\frac{1}{\sqrt{\left[1-\left(\frac{f}{f_{X}}\right)^{2}\right]^{2}+\left(2 h_{X} \frac{f}{f_{X}}\right)^{2}}}
$$

and

$$
G_{Y}(f)=\frac{1}{\sqrt{\left[1-\left(\frac{f}{f_{Y}}\right)^{2}\right]^{2}+\left(2 h_{Y} \frac{f}{f_{Y}}\right)^{2}}},
$$

respectively (e.g., Landschulze and Mjelde, 2014), where we suppose natural vibrations with one degree of freedom and neglect higher modes. The parameters $f_{X}$, $f_{Y}, h_{X}$, and $h_{Y}$ are natural frequencies and damping constants for the $\mathrm{X}$ and $\mathrm{Y}$ components, respectively. 

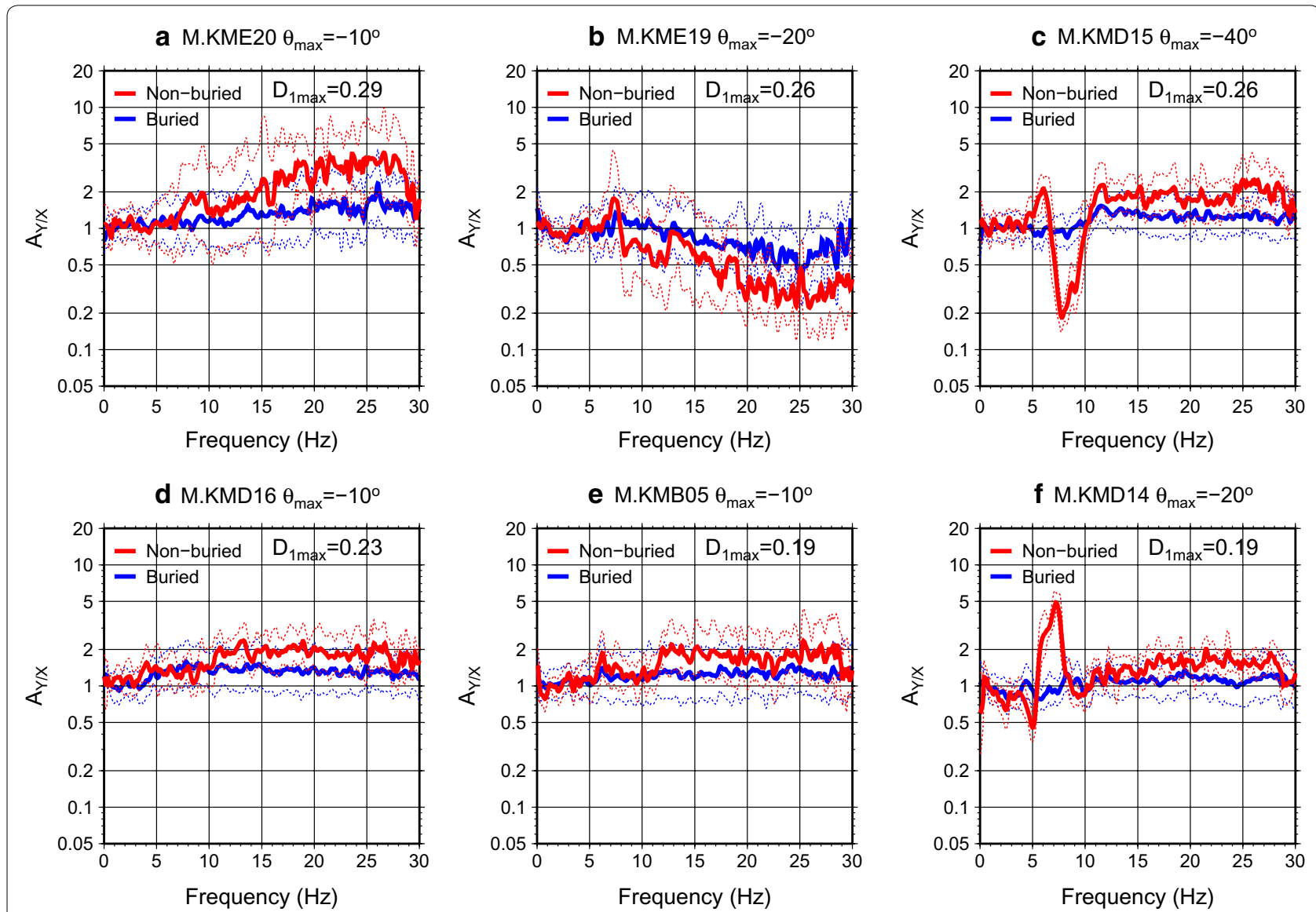

Fig. 10 Average $Y / X$ amplitude spectral ratio (solid red curves) and logarithmic standard deviation (dotted red curves) at $\theta=\theta_{\max }{ }^{\circ}$ obtained for six non-buried DONET1 stations with the largest $D_{1 \max }$. The $\theta_{\max }$ and $D_{1 \max }$ values for each station are written at the top and inside of each subfigure, respectively. Solid and dotted blue curves represent the average $Y / X$ amplitude spectral ratio and logarithmic standard deviation, respectively, obtained in the buried time period for each station, where the rotation angle $\theta$ is equal to $\theta_{\max }{ }^{\circ}$ estimated in the non-buried time period

Considering these two sources, the amplitude spectra of $\mathrm{X}$ and $\mathrm{Y}$ components excited in the pressure vessel are described by

$$
\left|U_{X}(f)\right|=\left[c+r G_{X}(f)\right]\left|S_{X}(f)\right|
$$

and

$$
\left|U_{Y}(f)\right|=\left[c+r G_{Y}(f)\right]\left|S_{Y}(f)\right|,
$$

respectively. These equations indicate that $c+r G_{X}(f)$ and $c+r G_{Y}(f)$ are amplitude response functions with respect to the incident $\mathrm{S}$-wave. Given that we assume $\left|S_{X}(f)\right|=\left|S_{Y}(f)\right|$ at coda time window, the Y/X amplitude spectral ratio is given by

$$
A_{Y / X}(f)=\left|\frac{U_{Y}(f)}{U_{X}(f)}\right|=\frac{c / r+G_{Y}(f)}{c / r+G_{X}(f)} .
$$

The $c / r$ ratio is the parameter that controls emergence of the natural vibrations. As $c / r$ increases (i.e., the coupling factor and conversion efficiency increases and decreases, respectively), the $\mathrm{Y} / \mathrm{X}$ amplitude spectral ratio approaches unity.

Figure 12 shows $\mathrm{Y} / \mathrm{X}$ amplitude spectral ratios modeled by Eqs. (7), (8), and (11) for several $c / r$ values, where other values are fixed as $f_{X}=18 \mathrm{~Hz}, f_{Y}=7 \mathrm{~Hz}$, and $h_{X}=h_{Y}=0.05$. The reproduced $\mathrm{Y} / \mathrm{X}$ amplitude spectral ratios form a peak and notch at natural frequencies of $f_{Y}$ and $f_{X}$, respectively. As $c / r$ increases, the peak and notch become smooth and the Y/X amplitude spectral ratio approaches unity. The $\mathrm{Y} / \mathrm{X}$ amplitude spectral ratio observed at S-net N.S6N14 is reasonably reproduced by the theoretical curve for $c / r=1$. As evident from Eqs. (7), (8), and (11), the DC level of $A_{Y / X}$ is unity regardless of the $c / r$ value. In fact, the observed $A_{Y / X}$ is close to unity in the frequencies of $<3 \mathrm{~Hz}$ at most stations having an " $\mathrm{N}$ "shape (Figs. 7 and 9).

Some strong assumptions are included in the proposed model. First, we assumed horizontal isotropy of incident S-coda wavefield and $\left|S_{X}(f)\right|=\left|S_{Y}(f)\right|$ as a result. This assumption may break down if the used earthquakes are distributed non-uniformly and the non-isotropic 


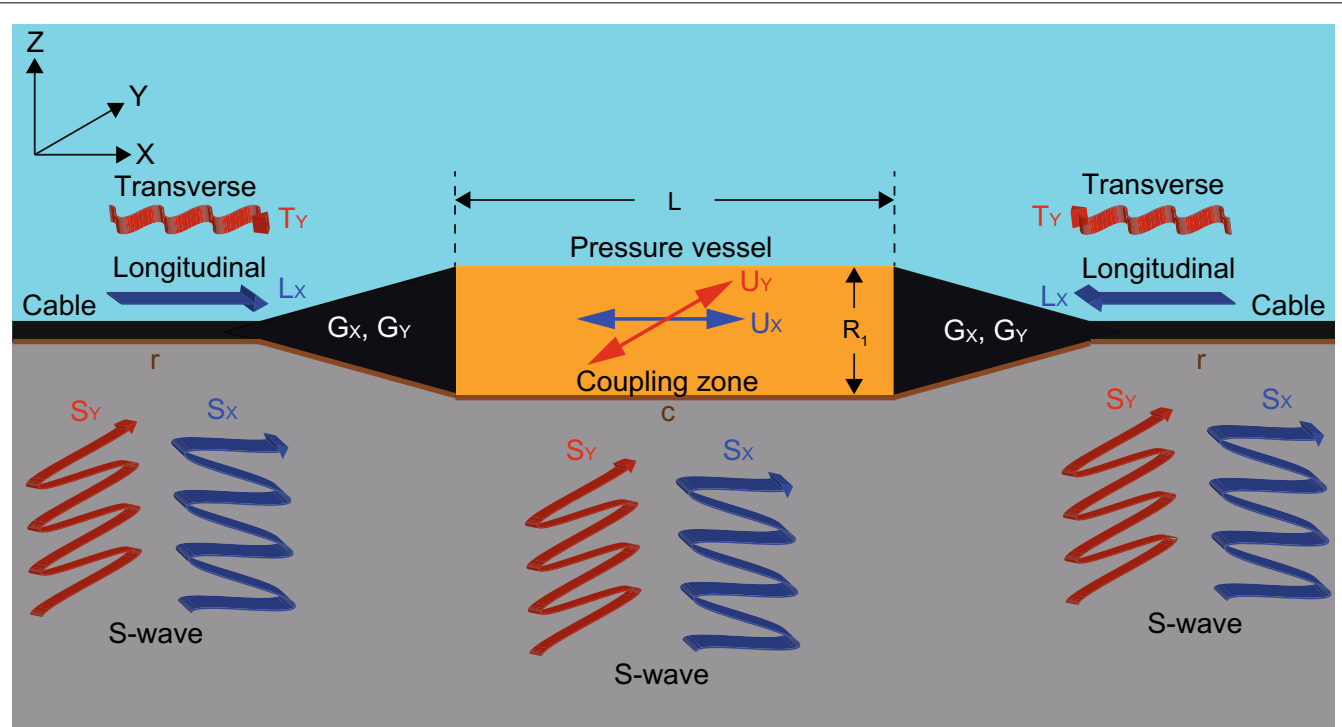

Fig. 11 Schematic illustration of the pressure vessel and cables placed on the seafloor. Some parts of the incident S-waves are directly transmitted into the pressure vessel and some parts are converted into guided waves (transverse and longitudinal waves). These waves vibrate the pressure vessel and excite motions $U_{X}$ and $U_{Y}$

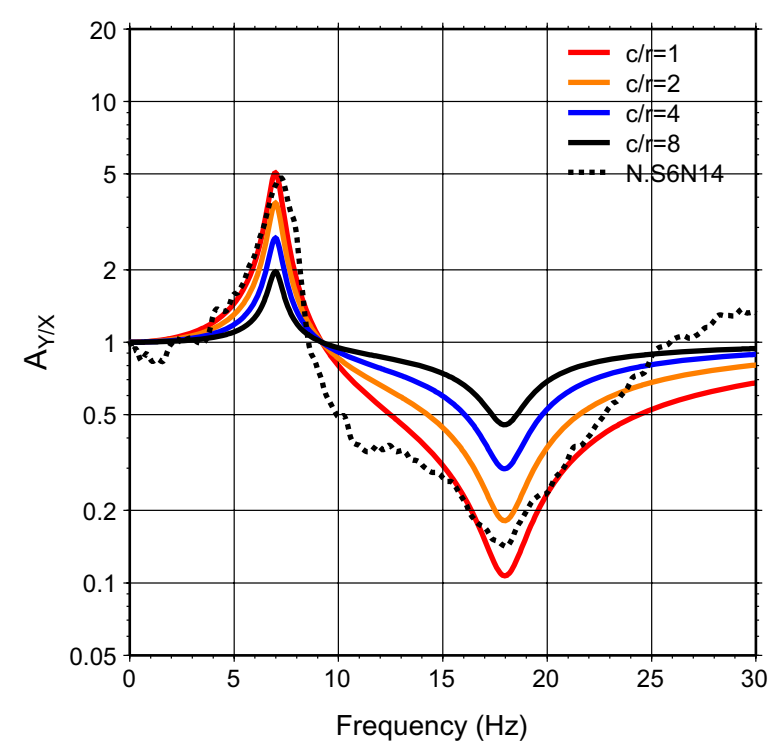

Fig. 12 Theoretical $Y / X$ amplitude spectral ratios calculated using a natural vibration model. Natural frequencies of the $X$ and $Y$ components were set to 18 and $7 \mathrm{~Hz}$, respectively, and the damping constant was set to 0.05 for both components. Different colors represent results for different $c / r$ values. The dotted black curve represents the $\mathrm{Y} / \mathrm{X}$ amplitude spectral ratio observed at station N.S6N14

component (e.g., T-waves, Rayleigh waves, etc.) is dominant in the incident wavefield. Moreover, since we neglected higher modes in evaluating amplitude response functions of the pressure vessel $\left(G_{X}\right.$ and $\left.G_{Y}\right)$, our model may not be appropriate at frequencies higher than the normal modes of the pressure vessel. In addition to this, although we assumed the coupling factor and the conversion efficiency are not frequency-dependent and common for the $\mathrm{X}$ and $\mathrm{Y}$ components, these assumptions may not be realistic. Previous studies have reported that the coupling factor is unity at frequencies lower than a threshold value, while it decreases as the frequency increases above the threshold value (e.g., Duennebier and Sutton, 1995). Therefore, this model needs to be considered with caution, especially at frequencies higher than the notch frequency. Nevertheless, this model shows in a general sense how the " $\mathrm{N}$ "-shape forms and how coupling affects excitation of the "N"-shape.

\section{Interpretation of natural frequencies}

In general, longitudinal, torsional, and bending vibrations are candidates of the natural vibrations of a cylindrical rod (e.g., Weaver et al. 1990). We regard this as a simplification of natural vibration of the pressure vessel. The natural frequencies of each mode $\left(f_{l}, f_{t}\right.$, and $f_{b}$, respectively) are given by

$$
\begin{aligned}
& f_{l}=\frac{\lambda_{n}}{2 \pi L} \sqrt{\frac{E}{\rho}}, \\
& f_{t}=\frac{\lambda_{n}}{2 \pi L} \sqrt{\frac{G}{\rho}},
\end{aligned}
$$

and 


$$
f_{b}=\frac{\lambda_{n}^{\prime 2}}{2 \pi L^{2}} \sqrt{\frac{E I}{\rho A}},
$$

respectively, where $L, E, \rho, G, I$, and $A$ are the length, Young's modulus, mass density, shear modulus, second moment of area, and cross section of the cylindrical rod, respectively. $I$ and $A$ are described by $I=\pi\left(R_{1}^{4}-R_{2}^{4}\right) / 4$ and $A=\pi\left(R_{1}^{2}-R_{2}^{2}\right)$, respectively, for a cylindrical rod with outer and inner radiuses $R_{1}$ and $R_{2}$, respectively. $\lambda_{n}$ and $\lambda_{n}$ ' are coefficients of the $n$-th mode; $\lambda_{0}=\pi$ and $\lambda_{0}{ }^{\prime}=4.73$ for two-free-edges boundary condition. We suppose the $\mathrm{X}$-component is dominated by longitudinal vibration, while the Y-component can be dominated by both torsional and bending vibrations, although we do not assess which is dominant in the Y-component.

From Eqs. (12) to (14), we derive

$$
\frac{f_{X}}{f_{Y}} \approx \frac{f_{l}}{f_{t}}=\sqrt{\frac{E}{G}}
$$

and

$$
\frac{f_{X}}{f_{Y}} \approx \frac{f_{l}}{f_{b}}=\frac{\lambda_{0}}{\lambda_{0}^{\prime 2}} L \sqrt{\frac{A}{I}}=\frac{\pi}{4.73^{2}} \frac{2 L}{\sqrt{R_{1}^{2}+R_{2}^{2}}}
$$

Considering the relationship between the Young's modulus and the shear modulus is given by $E=2 G(1+v)$, where the range of the Poisson's ratio $v$ is usually from 0 to 0.5 , we expect $f_{1} / f_{\mathrm{t}}$ ranges from 1.4 to 1.7. Considering the specifications of S-net (Kanazawa et al. 2016) and ETMC (Eguchi et al. 1998) pressure vessels summarized in Table 3 and $R_{2}$ value ranging from 0 to $R_{1}$, we expect $f_{1} / f_{\mathrm{b}}$ ranges from 2.7 to 3.8 for S-net and from 2.4 to 3.5 for ETMC.

Figure 13 shows a plot of peak frequency $f_{p}\left(\simeq f_{Y}\right)$ versus notch frequency $f_{n}\left(\simeq f_{X}\right)$ for S-net and ETMC stations with $D_{1 \max }>1.5 D_{2 \max }$. The $f_{p}$ and $f_{n}$ values are mostly distributed within $5-13 \mathrm{~Hz}$ and $10-23 \mathrm{~Hz}$, respectively, and the $f_{n} / f_{p}$ ratio is mostly between 1.4 and 3.8 , as expected from Eqs. (15) and (16).

From Eqs. (12) to (14), the following frequency ratios are also derived:

Table 3 Pressure vessel parameters for S-net and ETMC

\begin{tabular}{lll}
\hline Parameters & S-net & ETMC \\
\hline Length, $L(\mathrm{~m})$ & 2.3 & 1.6 \\
Mass density, $\rho\left(\mathrm{kg} / \mathrm{m}^{3}\right)$ & $5.4 \times 10^{3}$ & $4.1 \times 10^{3}$ \\
Outer radius, $R_{1}(\mathrm{~m})$ & 0.17 & 0.13 \\
\hline
\end{tabular}

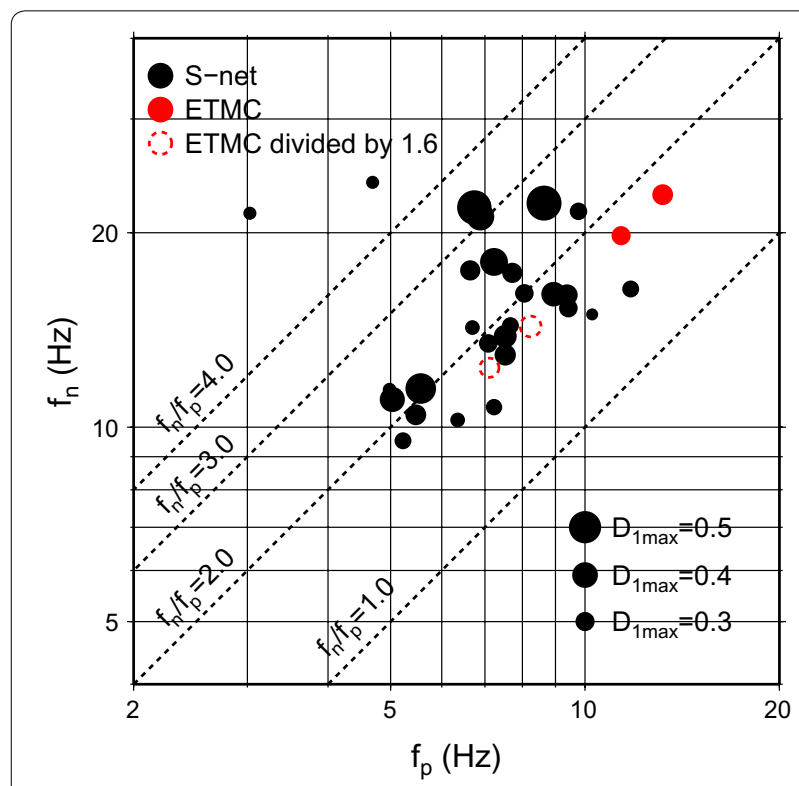

Fig. 13 Plot of peak $\left(f_{p}\right)$ versus notch $\left(f_{n}\right)$ frequencies observed for S-net (black circles) and ETMC (red circles) stations with $D_{1 \max }>1.5 D_{2 \max }$. The dotted red circles are the peak and notch frequencies of ETMC stations divided by 1.6

$$
\begin{aligned}
& \frac{f_{l, \mathrm{ETMC}}}{f_{l, \mathrm{~S}-\mathrm{net}}}=\frac{f_{t, \mathrm{ETMC}}}{f_{t, \mathrm{~S}-\mathrm{net}}}=\frac{L_{S-\text { net }}}{L_{E T M C}} \sqrt{\frac{\rho_{S-\text { net }}}{\rho_{\text {ETMC }}}}, \\
& \frac{f_{b, \mathrm{ETMC}}}{f_{b, \mathrm{~S}-\mathrm{net}}}=\frac{L_{S-\text { net }}^{2}}{L_{\text {ETMC }}^{2}} \sqrt{\frac{\rho_{S-\text { net }}\left(R_{1, \text { ETMC }}^{2}+R_{2, \text { ETMC }}^{2}\right)}{\rho_{\text {ETMC }}\left(R_{1, S-\text { net }}^{2}+R_{2, S-\text { net }}^{2}\right)}},
\end{aligned}
$$

where we assumed $E$ and $G$ are common for S-net and ETMC because the major structural component of both pressure vessels is beryllium copper. Substituting the values in Table 3 to Eqs. (17) and (18), we derive $f_{1, \mathrm{ETMC}} / f_{1, \mathrm{~S}-}$ net and $f_{\mathrm{t}, \mathrm{ETMC}} / f_{\mathrm{t}, \mathrm{S} \text {-net }}$ are 1.6 and $f_{\mathrm{b}, \mathrm{ETMC}} / f_{\mathrm{b}, \mathrm{S} \text {-net }}$ ranges from 1.3 to 2.6. In fact, the ETMC stations have relatively large $f_{p}$ and $f_{n}$ values as compared with most S-net stations (red circles in Fig. 13), and these values become comparable to the S-net counterparts after dividing by 1.6 (red dotted circles in Fig. 13).

Substituting $f_{t}=f_{b}=5-13 \mathrm{~Hz}$ and $f_{l}=10-23 \mathrm{~Hz}$ to Eqs. (12) and (13), we obtain the range of $E$ and $G$ as $10^{-3}$ to $10^{-1} \mathrm{GPa}$ in the order. This result appears to be too low for the Young's modulus of beryllium copper (ca. 130 GPa). However, we should note that computed $E$ and $G$ values correspond to the entire structure of the pressure vessel, including junctions and buffers. The elastic modulus of an entire structure is usually much lower than that of each component. Therefore, we think the ranges of the natural frequencies observed for the pressure vessel 
are physically possible, though the real value can only be confirmed through actual experiments.

\section{Problems and solutions when using in-line-type OBS records}

As we have shown, analyzing the $\mathrm{X}$ and $\mathrm{Y}$ components of in-line-type OBSs needs to be undertaken with care when the frequencies of $>3 \mathrm{~Hz}$ are used. For example, when estimating back azimuth using polarization of the first motion, the estimation will be seriously biased if the used record is suffered by natural vibrations of pressure vessel. The same is true for the $\mathrm{S}$-wave splitting analysis. For these analyses, it is necessary to correct phase spectra of the natural vibration as well as amplitude spectra to retrieve correct horizontal seismograms. Although estimation of the phase spectra was out of scope in this study, it is an urgent issue in near future. Analyses that require the vertical component $(\mathrm{U})$ only, such as estimating earthquake magnitudes, source spectra, coda- $\mathrm{Q}$, etc. may not be seriously affected by the natural vibrations of the pressure vessel because the vertical component is much less affected by coupling.

Because the difference between the $\mathrm{X}$ and $\mathrm{Y}$ components is insignificant at frequencies of $<3 \mathrm{~Hz}$, we think the natural vibrations of the pressure vessel are not excited at these low frequencies and analyses of these frequencies do not require correction of the $\mathrm{X}$ and $\mathrm{Y}$ components. Such analyses may include centroid moment tensor (CMT) inversion, waveform-based source inversion, receiver function analysis, seismic interferometry, and so on.

Our study has shown that the coupling of the pressure vessel to the seafloor influences the emergence of an "N"-shaped Y/X amplitude spectral ratio. Installation of the pressure vessel within a groove and/or burial are effective in suppressing natural vibrations of the pressure vessel. In fact, some studies have demonstrated that noise is dramatically reduced after burying OBSs (e.g., Araki et al. 2013). Therefore, such installation using underwater technologies to enhance the coupling is desirable when constructing an OBS network, not only to avoid the risk of cable damage but also to ensure high-quality records. In addition, it is recommended to carry out shaking experiments by placing the pressure vessel and cables on the bottom of water by imitating actual installation situation. Such experiments may enhance our understanding of how the natural vibrations are excited, and how much burial is needed to suppress these vibrations.

\section{Conclusion}

We examined Y/X coda amplitude spectral ratios for three OBS networks installed around Japan, and found anomalous "N"-shaped amplitude spectral ratios characterize many in-line-type OBSs of S-net and ETMC. Distinct peak and notch are found at around $5-13 \mathrm{~Hz}$ and $10-23 \mathrm{~Hz}$ in the amplitude spectral ratio, respectively. Such "N"-shape does not characterize buried in-linetype OBSs. Node-type OBSs of DONET1 also do not form the " $\mathrm{N}$ "-shape regardless of whether they are buried or not. We modeled the "N"-shaped Y/X amplitude spectral ratio by considering different modes of natural vibrations excited in a pressure vessel and insufficient coupling between the pressure vessel and the seafloor. When analyzing in-line-type OBS records at frequencies of $>3 \mathrm{~Hz}$, it is necessary to confirm whether the anomalous responses are included in the $\mathrm{X}$ and $\mathrm{Y}$ components. If necessary, correction of these components is required, or we should not use these components. It is recommended that OBSs be installed below the seafloor or within grooves dug in the seafloor to suppress natural vibration of the pressure vessel.

\section{Abbreviations}

OBS: Ocean bottom seismometer; S-net: Seafloor Observation Network for Earthquakes and Tsunamis; ETMC: Earthquake and Tsunami Monitoring Cable; DONET: Dense Oceanfloor Network system for Earthquakes and Tsunamis.

\section{Acknowledgements}

We thank Naoki Hayashimoto for valuable discussions and comments. Kenji Uehira provided us the burial information of S-net. Comments by Takuji Yamada, the associate editor, and two anonymous reviewers were helpful to improve quality of the manuscript. Seismic Analysis Code (SAC; Helffrich et al. 2013) and Generic Mapping Tools (GMT; Wessel et al. 2013) were used for signal processing and figure plotting, respectively.

\section{Authors' contributions}

KS analyzed the data and drafted most of the manuscript. TN partly drafted the section "OBS networks of S-net, ETMC, and DONET" and partly created some figures. Both authors read and approved the final manuscript.

\section{Funding}

This research was funded by the Japan Society for Promotion of Science (Grant-No. 19H01982).

\section{Availability of data and materials}

S-net and DONET records are available from the NIED's data repository (https ://doi.org/10.17598/NIED.0007, https://doi.org/10.17598/NIED.0008). ETMC records are available from Hi-net download site (https://hinetwww11.bosai.go. jp/auth/download/cont/?LANG=en). The JMA unified hypocenter catalogue, which was compiled in cooperation with MEXT Japan, is available from the JMA webpage (https://www.data.jma.go.jp/svd/eqev/data/bulletin/hypo. $h \mathrm{tmll}$.

\section{Competing interests}

The authors declare that they have no competing interests. 
Author details

${ }^{1}$ National Research Institute for Earth Science and Disaster Resilience, 3-1 Tennodai, Tsukuba, Ibaraki 305-0006, Japan. ${ }^{2}$ Central Research Institute of Electric Power Industry, 1646 Abiko, Abiko, Chiba 270-1194, Japan.

\section{Appendix}

One important assumption of the S-coda analysis in this study is that the S-coda waves are composed of multiply scattered S waves and the wavefield is horizontally isotropic. However, the S-coda part may contain nonisotropic phases like $\mathrm{T}$-waves and/or Rayleigh waves. These phases may be dominant in the radial component. For such a case, if the epicenters of the used earthquakes are distributed unevenly around the cable axis direction (X-direction) and/or the direction perpendicular to the cable axis (Y-direction), the amplitude spectra of incident Rayleigh waves and T-waves cannot be cancelled out, which makes it difficult to interpret the "N"-shape properly.

To check whether the observed "N"-shape is influenced by non-isotropy of the incident wavefield or not, we compute the $\mathrm{Y} / \mathrm{X}$ amplitude spectral ratios using only earthquakes whose back azimuth is distributed within $45 \pm 15^{\circ}$ with respect to the direction of $\mathrm{X}$ and Y-axes (we call this the $45 \pm 15^{\circ}$ criterion). The direction of the $\mathrm{X}$ and Y-axes was referred from Takagi et al. (2019) for S-net and Nakano et al. (2012) and Nakano (2017) for DONET1. For ETMC, the direction of the X and Y-axes was visually estimated from Fig. 3 of Eguchi et al. (1998). For earthquakes satisfying this criterion, even if phases on the radial (or transverse) component dominate the $\mathrm{S}$-coda, they are projected on the $\mathrm{X}$ and $\mathrm{Y}$ components with similar amplitude because $\sin 45^{\circ}$ is equal to $\cos 45^{\circ}$. The effects of incident wavefield will be removed from the $\mathrm{Y} / \mathrm{X}$ amplitude spectral ratio for such a case.

Figure 14 shows the distribution of $D_{1 \max }$, which is the same as Fig. 5 except that only the earthquakes satisfying the $45 \pm 15^{\circ}$ criterion are used for computing the average Y/X amplitude spectral ratio. For S-net and ETMC stations, the pattern of $D_{1 \max }$ distribution is similar to that shown in Fig. 5. Figure 15 shows the Y/X amplitude spectral ratios for the selected S-net stations located at the water depths deeper than $1500 \mathrm{~m}$. The red and black curves are the spectral ratios using the earthquakes satisfying the $45 \pm 15^{\circ}$ criterion and those using all the available earthquakes (same as Fig. 7), respectively. The "N"-shape is clearly observed even if the earthquakes satisfying the $45 \pm 15^{\circ}$ criterion are used. The difference

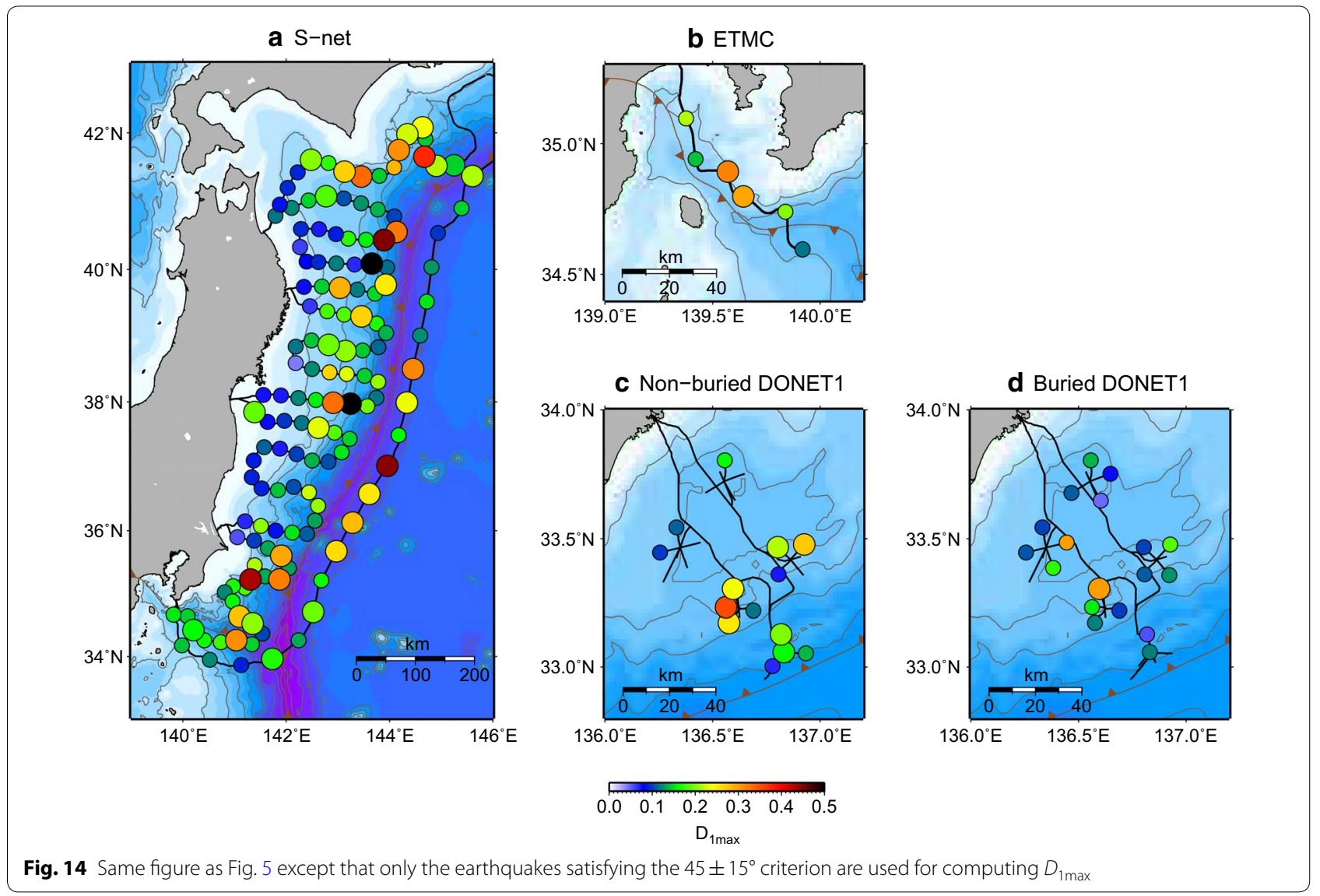



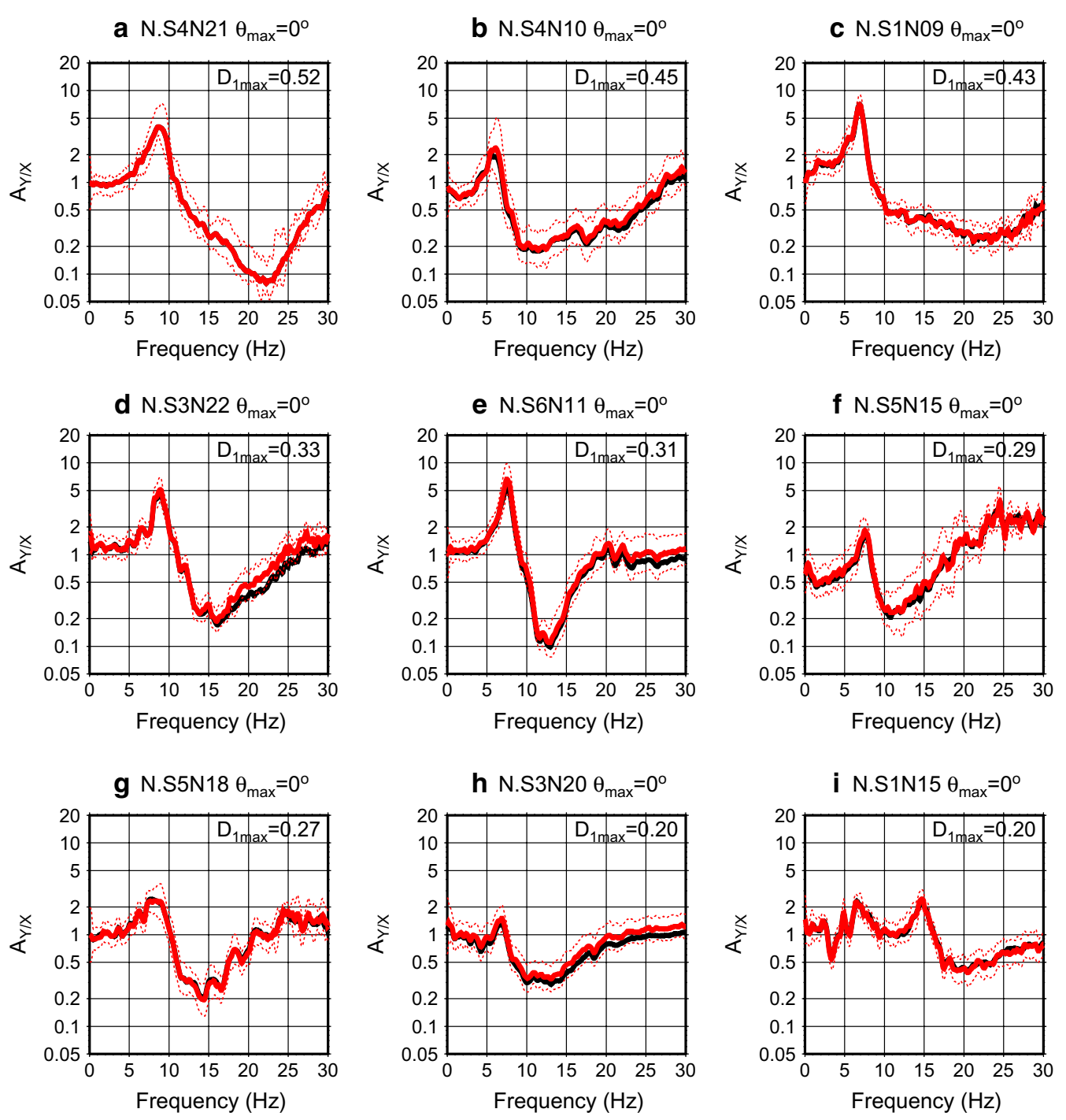

h N.S3N20 $\theta_{\max }=0^{\circ}$

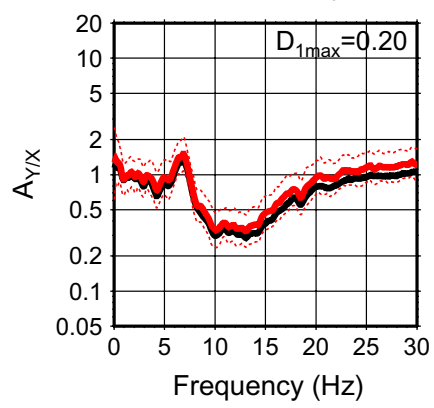

i N.S1N15 $\theta_{\max }=0^{\circ}$
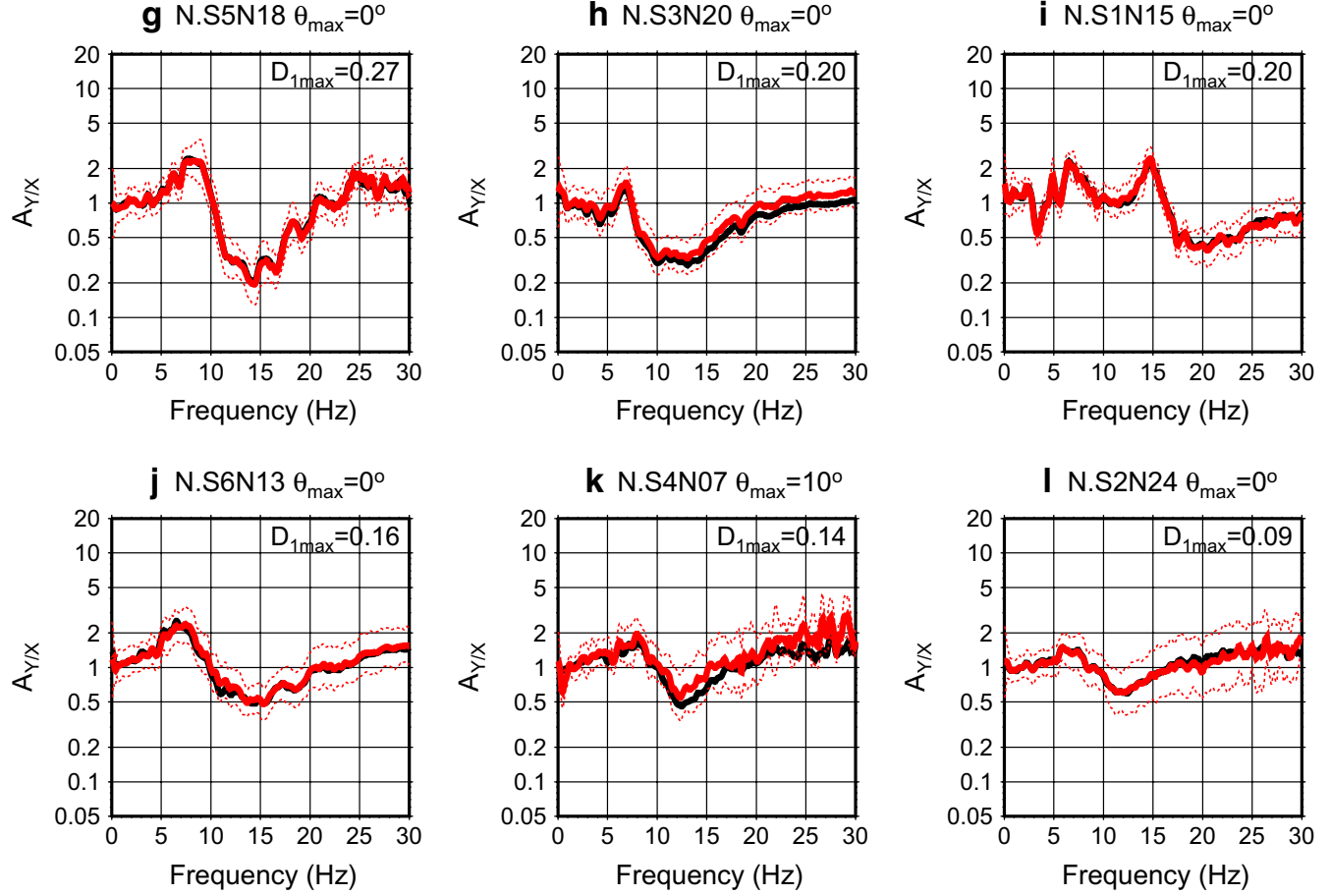

Fig. 15 Same figure as Fig. 7 except that only the earthquakes satisfying the $45 \pm 15^{\circ}$ criterion are used for computing the Y/X amplitude spectral ratio. Black curves are the result for the case of using all the available earthquakes (same as Fig. 7)

between the red and black curves is hardly seen for most stations.

Considering these results, we conclude that the "N"-shape is excited independently of the horizontal anisotropy of the incident wavefield. Note that this does not necessarily mean the incident wavefield is horizontally isotropic. 
Received: 9 March 2020 Accepted: 25 August 2020

Published online: 10 September 2020

\section{References}

Araki E, Yokobiki T, Kawaguchi K, Kaneda Y (2013) Background seismic noise level in DONET seafloor cabled observation network. In: IEEE International Underwater Technology Symposium (UT), pp. 1-4. https://doi. org/10.1109/UT.2013.6519858.

Ardhuin F, Gualtieri L, Stutzmann E (2019) Physics of ambient noise generation by ocean waves. In: Nakata N, Gualtieri L, Fichtner A (eds), Seismic Ambient Noise, Cambridge University Press.

Bagaini C, Muyzert E (2004) Calibration of cross-line components for seafloor 4C acquisition systems. Geophys Prospect 52(4):341-349. https://doi.org/ 10.1111/j.1365-2478.2004.00419.x

Duennebier FK, Sutton GH (1995) Fidelity of ocean bottom seismic observations. Mar Geophys Res 17(6):535-555. https://doi.org/10.1007/BF012 04343

Equchi T, Fujinawa Y, Fujita E, Iwasaki SI, Watabe I, Fujiwara H (1998) A realtime observation network of ocean-bottom-seismometers deployed at the Sagami trough subduction zone, central Japan. Mar Geophys Res 20(2):73-94. https://doi.org/10.1023/A:1004334021329

Fujiwara N, Hishiki K, Katayama T (2010) Ocean-bottom seismographic observation systems. NEC Tech J 5(1):56-60

Hayashimoto N, Nakamura T, Hoshiba M (2016) Stability of ocean bottom seismograph data exposed to strong shaking: Efforts for utilizing OBS for earthquake early warning. In: ECGS \& ESC/EAEE Joint Workshop Proceedings: 41-49.

Helffrich G, Wookey J, Bastow I (2013) The seismic analysis code: A primer and user's guide. Cambridge University Press, Cambridge

Kanazawa T, Uehira K, Mochizuki M, Shinbo T, Fujimoto H, Noguchi S et al (2016) S-net project, cabled observation network for earthquakes and tsunamis. Suboptic, Dubai

Kaneda Y, Kawaguchi K, Araki E, Matsumoto H, Nakamura T, Kamiya S et al. (2015) Development and application of an advanced ocean floor network system for megathrust earthquakes and tsunamis. In: Favali P, Beranzoli L, De Santis A (eds) Seafloor Observations: A New Vision of the Earth from the Abyss. Springer, Berlin, Heidelberg. https://doi. org/10.1007/978-3-642-11374-1_25.

Kawaguchi K, Kaneko S, Nishida T, Komine T (2015) Construction of the DONET real-time seafloor observatory for earthquakes and tsunami monitoring. In: Favali P, Beranzoli L, De Santis A (eds) Seafloor Observations: A New Vision of the Earth from the Abyss. Springer, Berlin, Heidelberg.

Kubota T, Saito T, Suzuki W (2020) Millimeter-scale tsunami detected by a wide and dense observation array in the deep ocean: Fault modeling of an Mw 6.0 interplate earthquake off Sanriku, NE Japan. Geophys Res Lett 47(4). https://doi.org/10.1029/2019GL085842.

Landschulze M, Mjelde R (2014) Azimuth-dependent ocean bottom cable receiver coupling to the seafloor. Geophysics 79(6):21-29. https://doi. org/10.1190/geo2013-0330.1

Landschulze M, Mjelde R (2016) Relative seismic receiver coupling estimation: a method using a probabilistic approach. Mar Geophys Res 37(4):245256. https://doi.org/10.1007/s11001-016-9282-3
Mochizuki M, Kanazawa T, Uehira K, Shimbo T, Shiomi K, Kunugi T et al (2016) S-net project: Construction of large scale seafloor observatory network for tsunamis and earthquakes in Japan. Paper presented at AGU Fall Meeting, Moscone Center, San Francisco, California, 12-16 December 2016.

Nakamura T, Hayashimoto N (2019) Rotation motions of cabled ocean-bottom seismic stations during the 2011 Tohoku earthquake and their effects on magnitude estimation for early warnings. Geophys J Int 216(2):14131427. https://doi.org/10.1093/gji/ggy502

Nakano M, Tonegawa T, Kaneda Y (2012) Orientations of DONET seismometers estimated from seismic waveforms. JAMSTEC Report of Research and Development 15:77-89 (in Japanese with English abstract)

Nakano M (2017) Orientations of DONET2 seismometers estimated from seismic waveforms. JpGU-AGU joint meeting 2017, STT59-P03 (in Japanese).

National Research Institute for Earth Science and Disaster Resilience (2019) NIED DONET. https://doi.org/10.17598/nied.0008.

National Research Institute for Earth Science and Disaster Resilience (2019) NIED S-net. https://doi.org/10.17598/nied.0007.

Nishikawa T, Matsuzawa T, Ohta K, Uchida N, Nishimura T, Ide S (2019) The slow earthquake spectrum in the Japan Trench illuminated by the S-net seafloor observatories. Science 365(6455):808-813. https://doi.org/10.1126/ science.aax 5618

Ohsaki Y (1994) New - Introduction to spectral analysis of earthquake motion, Kajima Institute Publishing (in Japanese).

Sato H, Fehler MC, Maeda T (2012) Seismic wave propagation and scattering in the heterogeneous earth. Springer-Verlag, Berlin, Heidelberg

Takagi R, Uchida N, Nakayama T, Azuma R, Ishigami A, Okada T et al (2019) Estimation of the orientations of the S-net cabled ocean-bottom sensors. Seismol Res Lett 90(6):2175-2187. https://doi.org/10.1785/0220190093

Tanaka S, Matsuzawa T, Asano Y (2019) Shallow low-frequency tremor in the northern Japan Trench subduction zone. Geophys Res Lett 46(10):52175224. https://doi.org/10.1029/2019GL082817

Uehira K, Kanazawa T, Mochizuki M, Fujimoto H, Noguchi SI, Shinbo et al (2016) Outline of seafloor observation Network for Earthquakes and Tsunamis along the Japan Trench (S-net). Paper presented at EGU General Assembly, Vienna, Austria, 17-22 April 2016.

Weaver W Jr, Timoshenko SP, Young DH (1990) Vibration problems in engineering. John Wiley \& Sons, New York, United States

Wessel P, Smith WHF, Scharroo R, Luis J, Wobbe F (2013) Generic Mapping Tools: Improved version released. Eos 94(45):409-410. https://doi. org/10.1002/2013EO450001

Woje G, Berg EW, Rykkelid JI, Svendsen $\varnothing$, Aanensen $\varnothing$ (2002) Vector fidelity analyses of seafloor seismic data. Paper presented at $64^{\text {th }}$ EAGE Conference \& Exhibition, Fortezza da Basso, Italy, 27-30 May 2002.

\section{Publisher's Note}

Springer Nature remains neutral with regard to jurisdictional claims in published maps and institutional affiliations.

\section{Submit your manuscript to a SpringerOpen ${ }^{\circ}$ journal and benefit from:}

- Convenient online submission

- Rigorous peer review

- Open access: articles freely available online

- High visibility within the field

- Retaining the copyright to your article

Submit your next manuscript at springeropen.com 